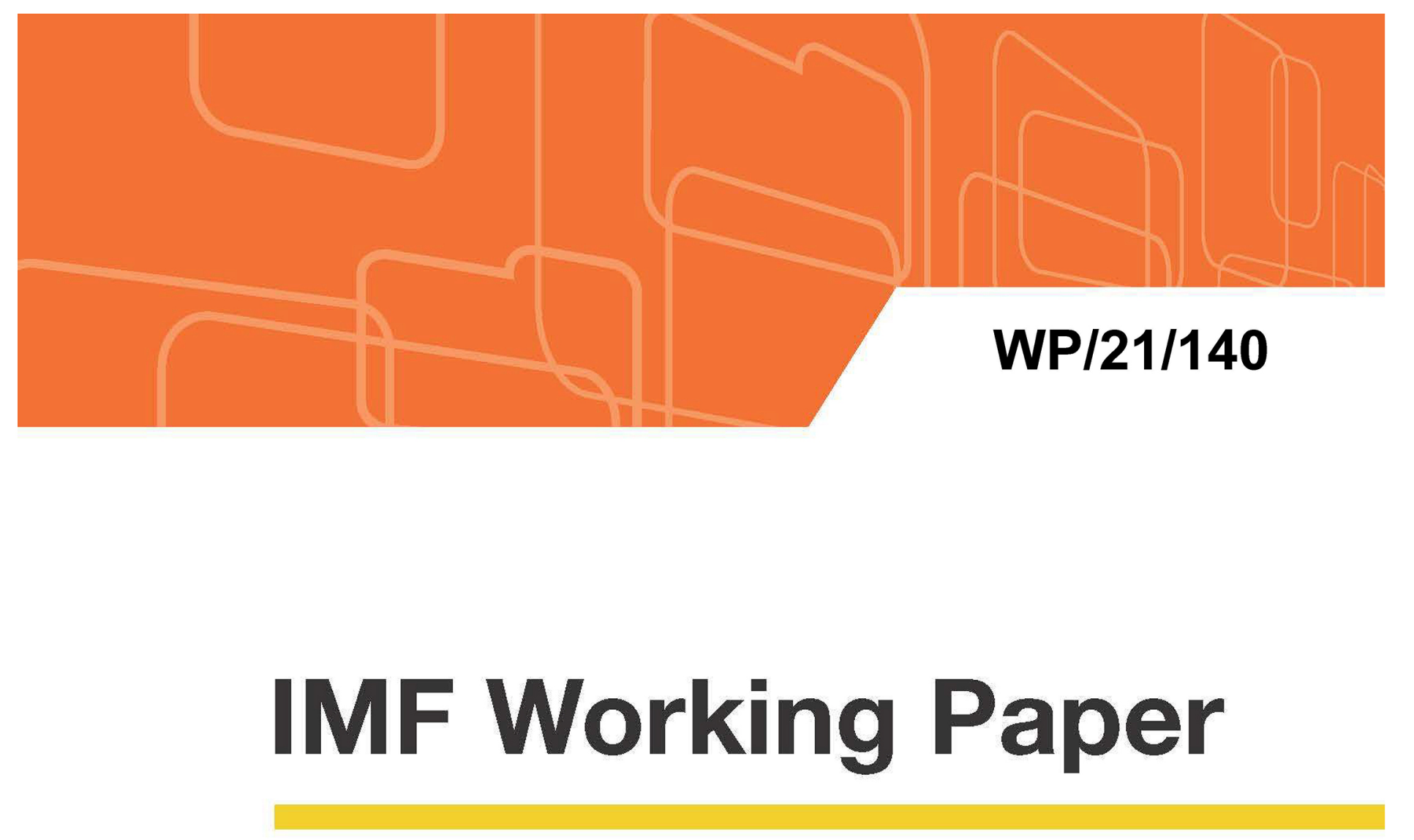

\title{
Employment Effects of Environmental Policies - Evidence From Firm-Level Data
}

\author{
by Adil Mohommad
}




\title{
IMF Working Paper
}

\author{
Research Department
}

\section{Employment Effects of Environmental Policies - Evidence From Firm-Level Data}

\author{
Prepared by Adil Mohommad
}

Authorized for distribution by Oya Celasun

May 2021

\section{IMF Working Papers describe research in progress by the author(s) and are published to} elicit comments and to encourage debate. The views expressed in IMF Working Papers are those of the author(s) and do not necessarily represent the views of the IMF, its Executive Board, or IMF management.

\begin{abstract}
The employment impact of environmental policies is an important question for policy makers. We examine the effect of increasing the stringency of environmental policy across a broad set of policies on firms' labor demand, in a novel identification approach using Worldscope data from 31 countries on firm-level CO2 emissions. Drawing on evidence from as many as 5300 firms over 15 years and the OECD environmental policy stringency (EPS) index, it finds that high emission-intensity firms reduce labor demand upon impact as EPS is tightened, whereas low emission-intensity firms increase labor demand, indicating a reallocation of employment. Moreover, tightening EPS during economic contractions appears to have a positive effect on employment, other things equal. Quantifications exercises show modest positive net changes in employment for market-based policies, and modest negative net changes for non-market policies (mainly emission quantity regulations) and for the combined aggregate EPS. Within market-based policies, the percent decline in employment in high-emission firms (correspondingly the increase in low-emission firms) for a unit change in a policy index is smallest (largest) for trading schemes ("green" certificates, and "white" certificates)—although stringency is not comparable across indices. Finally, the employment effects of EPS are not persistent.
\end{abstract}

JEL Classification Numbers: Q52, Q58

Keywords: Environmental regulation, Employment Author's E-Mail Address: amohommad@,imf.org 


\section{A. Introduction}

The climate crisis is intensifying, and the window to prevent irreversible damage from climate change is narrowing quickly. The October $2020 \mathrm{WEO}$ lays out a comprehensive policy package to reduce global carbon emission to net-zero by 2050, which is necessary to meet the 2015 Paris Agreement climate target of keeping global temperature increases by 2100 to below $2^{\circ} \mathrm{C}$, and ideally $1.5^{\circ} \mathrm{C}$. The policy package includes carbon taxation, along with a green infrastructure push that, along with helping reduce emissions and easing the adjustment to carbon taxation, would assist in transitioning workers away from sectors that would be impacted by carbon taxes, such as fossil fuel industries and high emission sectors more broadly. ${ }^{1}$

The employment impact of implementing tighter environmental policies is an important question for policy makers and is the focus of this paper. This is particularly pressing in the current conjuncture where the global coronavirus pandemic has extracted a heavy price on employment. It would be difficult for policy makers to implement more restrictive environmental policies if they were to lead to further job-losses in the economy. It thus becomes vital to assess what the effects of implementing tighter environmental policies on employment are. This is the question addressed by this paper: how does increasing the stringency of environmental policy impact labor demand, and how does this impact vary by the type of policies, and by the type of economic activity.

\section{B. Conceptual framework and related literature}

Conceptually, the impact is ambiguous. Increasing the stringency of environmental policy is a supply (cost) shock for all firms which would lead to a decline in firms' labor demand-the socalled output channel. This would vary in accordance with a firm's energy or emission-intensity (and the elasticity of demand for the firm's output); with more emission-intensive firms experiencing a bigger vertical shift in the supply curve (Yamazaki 2017). To take a specific example, a tightening in environmental regulation on emissions may requires firms to invest in capital stock that increases energy efficiency or reduces emissions ("abatement capital"). The increase in demand for capital, and thus in its rental rate $r$, would cause output to decline for all firms (Deschene 2018). An environmental tax, like a carbon tax, would similarly raise the marginal cost for all firms, reducing output and labor demand. The ambiguity arises due to substitution effects. Higher $r$ causes a substitution of capital for labor as capital is now relatively costlier. There is also an energy-for-labor substitution channel (Deschene 2010, Yamazaki, 2017) whereby firms substitute costlier energy for more labor in response to policies that increase energy costs. ${ }^{2}$ In addition, demand for labor may also increase among firms with lower emissionintensity as the relative price of low-emission intensive goods falls (due to demand switching to the extent that higher costs face by high-emission firms are passed on to consumers), although firms would also face a negative income effect on demand due to overall higher costs. Note that this paper does not try to distinguish between these effects, but the results may be interpreted in light of these channels.

${ }^{1}$ Given constraints in on the acceptability of carbon pricing, such policies may also need to be reinforced with less efficient but more acceptable policies such as feebates, or regulations, which do not have the same impact on the price of energy but would encourage switching to greener technologies (see Fiscal Monitor, IMF October 2019).

2 A firm's ability to do so will depend on factors including degree of homogeneity of the production function, and market power (see Deschene 2010). 
This paper is related to literature examining the impact of environmental policies at the firm level. Among these, Kahn (1997) examines the effect of particulate matter (PM) regulation in the United States and finds that employment growth was weaker in plants located in "nonattainment" areas (i.e., areas that did not meet the national air quality standard) in certain sectors, where policies regulating PM emission would be more likely to be binding. Similarly, Greenstone (2002) found that in a large sample of U.S. plants, carbon monoxide and ozone regulations had strong depressing effects on labor demand in non-attainment counties, especially among industries that emitted multiple pollutants (e.g., pulp and paper, and petroleum refining industries). More recently, Liu and others (2017) use plant-level data for the textile printing and dyeing industry (TPD) from the Yangtze delta region of China and a similar location-specific identification strategy. They show that TPD firms impacted by more stringent waste-water regulations applied to firms near lake Tai in the Jiangsu region reduced labor demand by 7 percent relative to the control group of TPD firms in the broader Yangtze delta region. ${ }^{3}$

Distinct from these studies, a novel feature of this paper is the use of firm-level CO2 emission data from Worldscope to identify climate policy effects. The approach involves taking the actual $\mathrm{CO} 2$ emissions at the firm level to distinguish firms' exposure to tighter environmental policies, as opposed to relying on location to identify the effects of policy, as firms could differ in their emissions even within the same location and same sector, potentially weakening the identification. Identification based on actual CO2 emissions avoids this issue. The use of emission-intensity as a source of variation is also adopted in recent research on the effects of implementing revenue-neutral carbon tax in the province of British Columbia in Canada in 2008. Using provincial level sectoral employment data and national level CO2 emission intensity of different sectors level), Yamazaki (2017) finds the implementation of this policy led to a fall in employment in carbon-intensive (and trade-exposed) sectors, offset by an increase in employment in low-carbon industries such as services. ${ }^{4}$

However, a limitation of this approach is that it limits the sample size as emission data at the firm level is relatively sparse. Thus, in a second step, this paper complements the firm-level emission-based identification with an approach proxying emission-intensity with the firms' sector, taking the a-priori view that certain sectors (e.g. fossil fuels or energy intensive manufacturing industries) will be more emission-intensive than others like services-a view that is also supported by the data.

A second novel feature of this paper is that it considers several types of environmental policies, not limited to a single policy such as carbon taxes for example, which has been a focus of some of the recent literature. The policy variable employed in this paper is the OECD index of environmental policy stringency (EPS), which aggregates the stringency of a number of different types of environmental policies. These various policies can be further grouped into two main sub-indices capturing market-based and non-market policy stringency. Figure 1 shows the

\footnotetext{
${ }^{3}$ Deschene (2018) lays out a brief overview of the literature with regard to environmental policy and employment effects.

${ }^{4}$ Yamazaki (2017) argues that emission intensity at the national level is a sufficient proxy for provincial level emission intensity of different sectors, as relatively clean sectors in one province are likely to also be relatively clean in other provinces, even if they differ within sector across provinces in the absolute emission intensity. Even so, individual firms within a broadly defined sector may differ substantially in emission intensity, which will be obscured at the aggregated sector level.

It is useful to note that the effects of British Columbia policy are debated. While Yamazaki (2017) finds an overall positive but modest $(0.74$ percent) effect on provincial employment. However, using household data, Yip (2018) comes to a different conclusion: the policy resulted in a 1.3 percentage point increase in the overall unemployment rate in the province, with the increase being disproportionately higher among lowand medium- skilled workers. In a cross-country setting, Stock and Metcalf (2020) do not find evidence of significant negative employment effects of carbon taxes using aggregate data for a set of EU countries.
} 
evolution of EPS stringency in the sample over time. Overall, aggregate EPS has increased over time in the sample, as both market and non-market policy stringency has increased. It is important to keep in mind that a given index may be compared across countries but comparing across indices is less meaningful. ${ }^{5}$ The market and nonmarket sub-indices encompass a variety of policies_-including taxes on fuel; trading schemes including carbon emission trading, green certificates and white certificates; feed-in-tariffs for wind

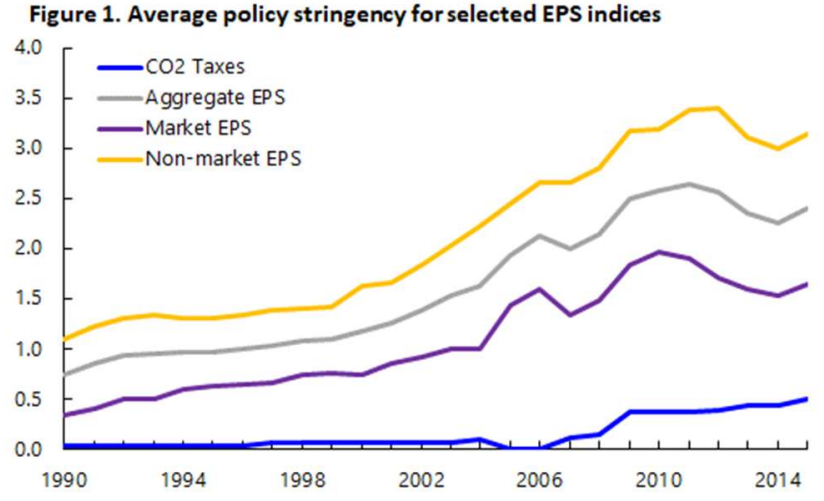

Sources: $O E C D$, and IMF staff calculations. EPS = environmental policy stringency. Index ranges from 0 - 6 . and solar-based electricity; emission limits; and R\&D subsidies. The impact of each of these subcomponents of the main indices on labor demand are also considered in this paper. ${ }^{6}$

A third novel contribution of this paper is that it considers whether the cyclical position of the economy has an effect on the impact of tightening environmental policies. At the current conjuncture, with pandemic-related economic weaknesses afflicting a large number of countries, implementing policies that increase costs for firms in the midst of a downturn may not seem to be a good choice. However with nominal interest rates in many advanced economies at historic lows, tightening environmental policies may cause real rates to decline by pushing up inflation expectations, imparting a stimulating effect on labor demand. ${ }^{7}$

The main conclusions of this paper can be summarized as follows. (i) In the near term, stricter environmental policies lead to reduced labor demand among high-emission firms, and increased labor demand among low emission firms. Firms in carbon emission-intensive manufacturing (including chemicals, metals and minerals, paper and packaging, and food and beverages), show negative employment effects, as well as construction sector firms, while firms in the services sector show positive effects. (ii) Tightening environmental policies amid contractions appears to have a small positive employment effect, other things equal. This may reflect the impact of tighter environmental policies on cost-push inflation, lowering real interest rates and stimulating demand. (iii) The net effect of tighter environmental policies is modest. For example, a quantification exercise based on the employment data in the sample shows that a one-standard deviation tightening in aggregate EPS would result in employment losses of about 1 percent of aggregate employment. Such a quantification also shows that tighter market EPS results in a modest net employment gain while tighter non-market EPS in results in a modest net loss. (iv) The estimated magnitudes of employment effects differ across different types of market and non-market policies. For example, for market-based trading schemes, the positive employment

\footnotetext{
${ }^{5}$ Botta and Kozluk (OECD 2014). The EPS index and its subindices are scaled from $0-6$ (from low to high stringency) and can be compared over time and across countries for the same index. Since the index values are not expressed in terms of a common unit (like CO2 emissions, for example), it is not possible to compare across indices.

${ }^{6}$ Carbon taxation occupies prominent place in current discussions on climate policies. However, due to the relatively low levels of adoption of carbon taxation historically (Figure 1), there is little variation in the data used in the exercises in this paper, leading to statistically insignificant results, though coefficient signs are consistent with the intuition that high emissions intensity firms would be negatively affected whereas low emissions intensity firms would not.

${ }^{7}$ Eggertsson (2012) shows that under "emergency" conditions created by deflationary shocks, policies that would otherwise reduce output through loss of efficiency can be productive in the sense of increasing output and reducing/reversing deflation, by increasing inflation expectations, and lowering the real rate given price rigidities (in particular the zero lower bound for interest rates).
} 
effects for low-emission intensity firms is relatively large, and the negative employment effects on high-emission intensity firms is relatively small. In contrast, the estimates for taxes on emissions of nitrogen oxide has the opposite pattern. (v) Over the medium term, the impact of environmental policies appears to reverse and fade away, suggesting that firms undergo a period of adjustment due to tighter policies, but there do not appear toto be lasting effects beyond a 2year time horizon.

The main contribution of this paper is that it finds support for reallocation of labor across high and low-emission intensity firms for a broad set of environmental policies. It also shows that the impact on labor demand is not persistent over the medium term. A second contribution is that it examines the interaction of tighter policies with the business cycle in determining the employment effects, finding some evidence that labor demand could increase if environmental policies are tightened in recessions.

From a policy perspective, the results suggest that there are near-term transitional costs of tighter policies that would need to be addressed. Policies are needed to make it easier for workers to move from high-carbon to low-carbon sectors. This would involve reskilling the workforce, and creating job opportunities in green sectors to offset the loss of jobs in highcarbon sectors, for example through investment in green infrastructure. ${ }^{8}$ Policies may also need to have a regional focus, to assist laid-off workers in certain communities and areas which are predominantly fossil-fuel dependent, and to redevelop affected regions with a greater emphasis on low-carbon activities.

The plan of the paper is as follows. Part B lays out the empirical models that are estimated in the paper. Part $\mathrm{C}$ discusses data sources and Part D discusses the results of regression exercises. Finally, Part E concludes.

\section{Empirical specification}

The specification is built around estimating a labor demand equation. The estimating framework is taken from Van Reenen (1997) where firm-level employment is a function of wages, the rental rate of capital, and real capital stock, based on optimality conditions derived from a standard neoclassical model. The model is augmented with a climate policy stringency indicator that is country and year specific. The identification strategy is difference-in-difference; we assume that high-emission intensity firms are differently impacted from low-emission intensity firms by the increased stringency of climate policy. This is implemented by interacting the climate policy stringency variable with an indicator variable to capture firms' CO2 emission intensity. Following Van Reenen (1997), the estimation methodology is panel GMM to address endogeneity due to the presence of the lagged employment term on the right-hand side in the presence of fixed effects (Nickell bias).

The main estimating equation is

$$
n_{i, t}=\sum_{k=1}^{T} a_{k} n_{i, t-k}+\boldsymbol{b} \boldsymbol{X}_{i, j, t}+c_{1}\left[E P S_{j, t} \times d_{C}\right]+d_{C}+d_{i}+d_{j}+d_{t}+\varepsilon_{i, t} ; \text { where }
$$

\footnotetext{
${ }^{8}$ In the current context of the global COVID-19 pandemic, green infrastructure investment policy has the added advantage of supporting a jobrich recovery (See IMF WEO Chapter 3, October 2020).
} 


$$
d_{C}=1 \text { if CO2 emissions intensity = "high", } 0 \text { otherwise }
$$

The subscripts $i, j, t$ refer to firm, country, and time (year), and $k$ is a lag-length. All variables are expressed in logs, except the environmental policy stringency (EPS) indicator which enters in levels (see below for details). The dummy variable $d_{C}$ indicates whether a firm is high (low) emission-intensity (see Section C below). Firm-level employment $n_{i, t}$ is regressed on its own lags, a vector of controls $\boldsymbol{X}_{i, j, t}$, and firm, country, and year fixed effects $d_{i}, d_{j}$, and $d_{t}$ respectively. The vector $\boldsymbol{X}_{i, j, t}$ includes EPS, and (logs of) firm-level average annual employee wages; real capital stock; and the rental rate of capital. Additional specifications also include controls for the output gap. ${ }^{9} E P S_{j, t} \mathrm{x} d_{C}$ is the interaction of interest, where EPS refers to the value of the selected environmental policy indicator in country $j$ and time $t$. This specification is referred to below as Specification 1.

A second specification proxies emission intensity by firms' sector. This enlarges the sample size as it does not rely on firms' CO2 emission data and can include all firms with adequate unbroken spells of data on employment and the firm-level explanatory variables (see Section $\mathrm{C}$ below for more details). In this specification, the emission-intensity dummy $d_{C}$ is replaced with a sector dummy $d_{S}$ :

$$
n_{i, t}=\sum_{k=1}^{T} a_{k} n_{i, t-k}+\boldsymbol{b} \boldsymbol{X}_{i, j, t}+c_{1}\left[E P S_{j, t} \times d_{S}\right]+d_{S}+d_{i}+d_{j}+d_{t}+\varepsilon_{i, t} \text {; where }
$$

The indicator $d_{S}$ separately identifies 6 sectors: fossil fuel industries, high-emission manufacturing industries, other (low-emission) manufacturing industries, services, construction (residential, commercial, and industrial), and transport industries. High emission industries include chemicals, metals and minerals, paper and packaging, and food industries. ${ }^{10}$ The definition of sectors by Worldscope codes and includes emission-intensity of the median firm in the sector are shown in Table 3.

Our prior is that firms engaged in high-emission intensity activities (including emissions embodied in inputs) or activities related to the production of carbon-intensive energy will be more negatively impacted by tighter environmental policy due to the increase in costs- the socalled output channel. In low-emission intensity firms, the output channel may be weaker as the increase in costs is lower. The substitution effects would also further dampen the negative effect on employment via the output channel. In addition, demand switching to the relatively cheaper low-emission intensity good may even have positive employment effects.

\footnotetext{
${ }^{9}$ All firms in a country are thus assumed to have the same rental rate of capital which is a simplifying assumption. This is similar to Van Reenen (1997) who proxies the rental rate with year fixed effects for a panel of U.K. firms.

${ }^{10}$ Evidence suggests that these industries are among the heaviest emitters among manufacturing industries. For example, they account for more than 90 percent of manufacturing sector CO2 emissions in the EU. See "Sectoral Policies for Climate Change Mitigation in the EU," IMF 2020.
} 


\section{Data}

The principle data source for this exercise is Worldscope global data on the balance sheets of listed firms. From this dataset we obtain annual firm-level data on total number of employees, total staff costs, and value of physical capital in machinery and in buildings. Firm wages are calculated as total staff costs per employee, ${ }^{11}$ and a value of the real stock of physical capital is derived by summing up the deflated values of machinery and building capital stock, using corresponding price deflators (see below). A key motivation for using Worldscope data as opposed to other firm level databases such as Orbis, is the availability of firm-level CO2 emissions data, available in Worldscope environmental-social-governance (ESG) indicators suite. We use data on total CO2-equivalent emissions (in tons per year), which includes a firm's direct as well as indirect (upstream) emissions, scaled by total employment of the firm to obtain emission intensity. ${ }^{12}$

Employment and CO2 emission data reporting is somewhat limited among Worldscope firms. Only a subset of the original set of more than 42,000 firms report employment and staff costs data continuously for several years; and fewer still report CO2 emissions data. This restricts the sample to a smaller set of firms reporting unbroken spells of data on employment, staff costs, and capital stock. Only the longest spell of continuous data for each firm is selected. Further, only firms reporting at least 3 instance of $\mathrm{CO} 2$ emissions are included in the sample. Firms that report CO2 data do so only intermittently. In light of this, a firm is coded into a high or low emission category depending on the empirical distribution of emission-intensity in each countryyear. A firm is coded as high-emission intensity $\left(d_{C}=1\right)$ if its emissions-to-employment ratio exceed the median of the country-year distribution in any year for which it reports data. Thus, emission-intensity is a time-invariant property of the firm in this setup. Though firms' emissions vary from year-to-year, the time-invariance of the $\mathrm{CO} 2$ emission intensity indicator variable does not appear to be problematic, given that the levels of emissions among low and high emission firms remain quite different. The emissions-to-employment ratio of median high-emission intensity firm is more than 12 times as large as that of the median low-emission intensity firms. The final samples consist of 670 firms taking into account the availability of CO2 emission data, and 5305 firms when using sectoral dummies to proxy emission-intensity instead. The data span 31 countries over $2000-2015 .^{13}$

\footnotetext{
${ }^{11}$ From the standard neoclassical model, labor demand may be expressed as a function of either nominal wages and the stock of capital (and the rental rate), or as a function of real wages and output. We have followed the former approach, in part due to lack of data on firm output (sales would be the proxy, and would difficult to express accurately in real terms in the absence of firm level price deflators), while disaggregated data on firms' building and machinery stock from Worldscope, and deflators at the country level for buildings and machinery (from Penn World Tables) are available. However, robustness checks of the main results controlling for real wages (deflated by country CPI) instead of nominal wages are presented as well.

${ }_{12}$ Total CO2 and CO2-equivalents include carbon dioxide (CO2), methane (CH4), nitrous oxide (N2O), hydrofluorocarbons (HFCS), perfluorinated compound (PFCS), sulfur hexafluoride (SF6), nitrogen trifluoride (NF3). Total CO2 emission = direct (scope1) + indirect (scope 2). Scope $1=$ direct emissions from sources that are owned or controlled by the company. Scope $2=$ indirect emissions from consumption of purchased electricity, heat or steam which occur at the facility where electricity, steam or heat is generated. Note the this excludes emissions embodied in the supply chain (excluding energy inputs).

${ }^{13}$ The list of countries includes mainly advanced economies (Australia, Austria, Belgium, Canada, Czech Republic, Denmark, Finland, France, Germany, Greece, Hungary, Ireland, Italy, Japan, Netherlands, Norway, Poland, Portugal, Russia, Slovenia, Spain, Sweden, Switzerland, UK, and US), and some large emerging economies (Brazil, China, India, Indonesia, Russia, South Africa, and Turkey). In some specifications, Slovenia is not included in the country sample due to data limitations.
} 
The explanatory variable of interest is the OECD's environmental policy stringency (EPS) index. This index includes an extensive set of environmental policies over a long-run time-series. It includes cross-country comparable data for 33 OECD and emerging market countries between 1990-2015 for various policy indicators. A given index may be compared across countries, but comparisons across indices are less meaningful. The EPS index is measured on a scale from 0 to 6 for stringency of policies and these may be broadly classified into "market" and "non-market". The former includes taxes on the pollutants (NOx, SO2, CO2, and PM); trading schemes for $\mathrm{CO} 2$, and green and white certificates; and feed-in tariffs for solar and wind-based electricity generation. The latter include limits on emissions of PM, SO2 and NOx for newly built coalfired power plants, limits on sulphur content in diesel, and government R\&D expenditures for renewable energy technologies. The sub-indices of these policies are aggregated into "market" and "non-market" indices, and further aggregated into a single measure of overall EPS. The stringency of the various measures is quite varied, with non-market measures having come into force from the early 1990s onwards in most OECD countries, while carbon taxation has been sparingly implemented in a much smaller share of countries and other market measures such as trading schemes and FITs have become more popular from the early 2000s onwards (see WEO Chapter 3 October 2020).

Data for other covariates are as follows. In order to deflate the nominal value of capital stocks and obtain real values, we use respectively the annual series for the price of machinery and the price of building stock from Penn World Tables (PWT, version 9.1). In addition, we also use the annual data on the rental rate of capital from PWT to proxy for firm level R; thus each firm is assumed to face a common price of capital in a given country, generalizing the treatment in Van Reenen (1997) of capturing the rental rate with time-dummies (in a sample of UK firms). Finally, data on output gap estimates is taken from the IMF WEO database.

\section{E. Results}

This section discusses the main results from the empirical exercises outlined above. Specification 1 and 2 below examine the short-term impact of tighter environmental policies, with the identification based on emission-intensity and the sector of the firm respectively. The next set of results examines the interaction between cyclical conditions and tighter environmental policies. Following that is a set of results that discusses the impulse-responses showing the medium-term effects of changes in aggregate, market, and non-market EPS. Finally, regressions considering disaggregated policies that underly the broader market and non-market EPS indices are discussed.

Specification 1: high/low emission-intensity. To preview, the results from Specification 1 suggest that tighter EPS leads to a decrease in employment in high emission firms and an increase in low-emission firms. Table $2 \mathrm{~A}$ shows the results of Specification 1, with the emission intensity dummy based on emissions per employee and with contemporaneous policies. Column 1 shows the results of a standard labor demand equation, incorporating 2 lags of employment, 
and controlling for wages, the rental rate of capital, and the capital stock. The coefficient estimates are all highly statistically significant and have the expected sign with the respect to factor prices, the capital stock, as well as the lags of employment. The GMM specification includes up to 9 lags of the levels of the instrumented variables as indicated in the table.

In columns 2-5, the interaction term of the EPS indicator with the emission-intensity dummy is included. The interaction is negative in all cases, and statistically significant for aggregate EPS (column 2) and non-market EPS (column 5). ${ }^{14}$ Overall the results in Table $2 \mathrm{~A}$ suggest that tighter EPS leads to a decline in employment for firms with high emission intensity, whereas the effect is positive (but generally insignificant) for low emission intensity firms.

In Columns 6-9 we include the output gap term to capture local macroeconomic conditions, and also interact it with the EPS indicator. The coefficient on the output gap term is positive as expected (and significant in the case of market EPS). The interaction of output gap with EPS is negative (and again significant in the case of market EPS). This suggests that a larger negative output gap would be associated with more positive employment effects, other things equal. We focus more on this result in greater detail below.

In Table $2 \mathrm{~B}$, we consider the same policy indicators lagged by one period, to allow for the possibility that firms may adjust to policy changes with a lag. Also, in some cases a firm's fiscal year may end before policy changes in the calendar year, thus a lag would allow picking up employment effects if any among such firms. The results of this exercise are broadly similar, with stronger results for market EPS, as both market EPS and its interaction with emissionintensity are statistically significant. However in column 2, the output gap is not significant, and its interaction with market EPS, while negative and of similar size as in Table $2 \mathrm{~A}$, is no longer significant at conventional levels. ${ }^{15}$ Also, in both specifications, the coefficient on carbon tax (and its interaction with the emission intensity dummy) has the same pattern as aggregate, market and nonmarket EPS, but is insignificant.

The results in Table $2 \mathrm{~B}$ suggest that a 1 standard deviation tightening in the aggregate EPS indicator (based on the distribution over the entire sample period and across all countries) would lower employment in high-emission intensity firms by 5 percent, and raise employment in low-emission intensity firms by 3.3 (Figure 2). Aggregate EPS reflects the combined effects of changes

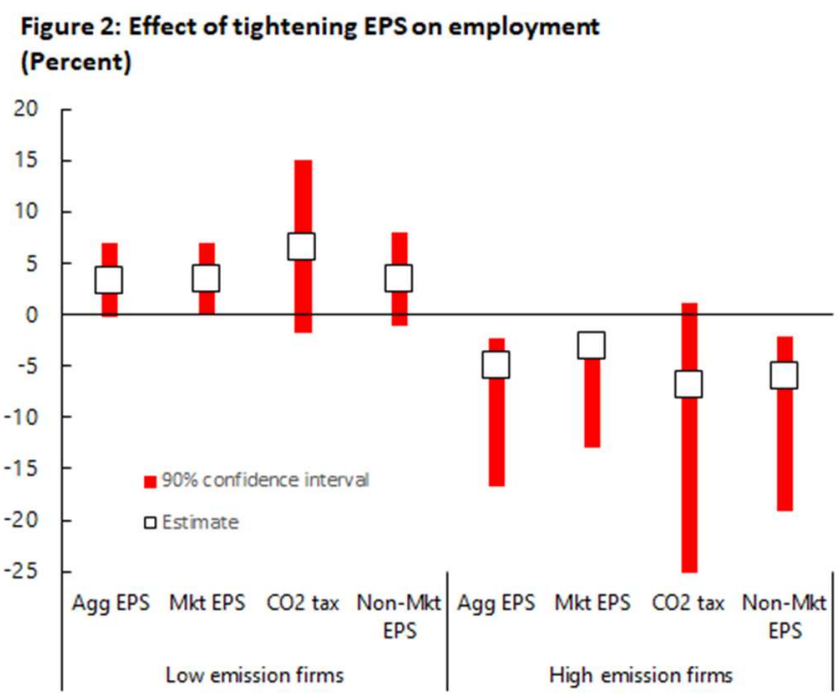

Sources: Worldscope, $O E C D$, and IMF staff estimates. EPS = environmental policy stringency. Figure shows point estimateand $90 \%$ confidence intervals of tightening the EPS indicator by 1-standard deviation of the distribution over all countries and years.

${ }^{14}$ The t-statistic is 1.5 in the case of the interaction with market EPS.

${ }^{15}$ The t-statistic falls to 1.6 . 
in both market and non-market policies. A 1-standard deviation tightening in the market EPS indicator would lower employment in high-emission intensity firms by 3.1 percent, while raising it in low-emission intensity firms by 3.5 percent. The negative effects are more sizable in the case of non-market EPS, whereby a 1-standard deviation tightening in the indicator would lower employment in high-emission firms by 6.1 percent and raise it in low-emission firms by 3.5 percent. The sizes of the effects are very similar based on estimates in Table $2 \mathrm{~A}$. It is useful to recall here that the 1 -standard deviation tightening in policies is not comparable as it is not expressed in terms of a common unit, such as a target level of emission reduction.

Thus, emission-intensity determines whether the effect of tighter environmental policies on firm employment is positive or negative. The main intuition for these results is that for high-emission intensity emission firms, the costs of more stringent climate policy are more likely to be binding leading to downward adjustments to output and employment, consistent with the negative coefficient on the interaction of EPS with the high-emission intensity dummy. ${ }^{16}$ Among lowemission intensity firms the positive coefficient on EPS may relate to the relative strength of the positive substitution effects (as described earlier) as compared to the (likely smaller) negative output effect, and due to demand switching in favor of low emission-intensity goods produced at relatively lower costs compared to high-emission intensity firms following tighter EPS.

Turning now the impact of tightening market EPS in relation to the cyclical conditions, we found that the interaction of the output gap with the market EPS indicator is significant and negative, indicating that tightening market EPS can have a positive employment effect in periods of economic contraction, other things equal. Indeed, the average marginal effects of market EPS are modestly positive under contractionary conditions and turn negative during highly expansionary periods (Figure 3). The estimates here suggest that in deep recessions, a 1 unit tightening in market EPS could actually increase employment by about 2 percent, other things equal. This effect is also observed in an alternative specification including interaction of EPS with a dummy variable set equal to 1 for different thresholds the output gap (below the $25^{\text {th }}$ percentile, and the $1^{\text {st }}$ percentile of the distribution (corresponding to about -1.5 percent and -6 percent of

Figure 3: Average marginal effects of tightening market EPS

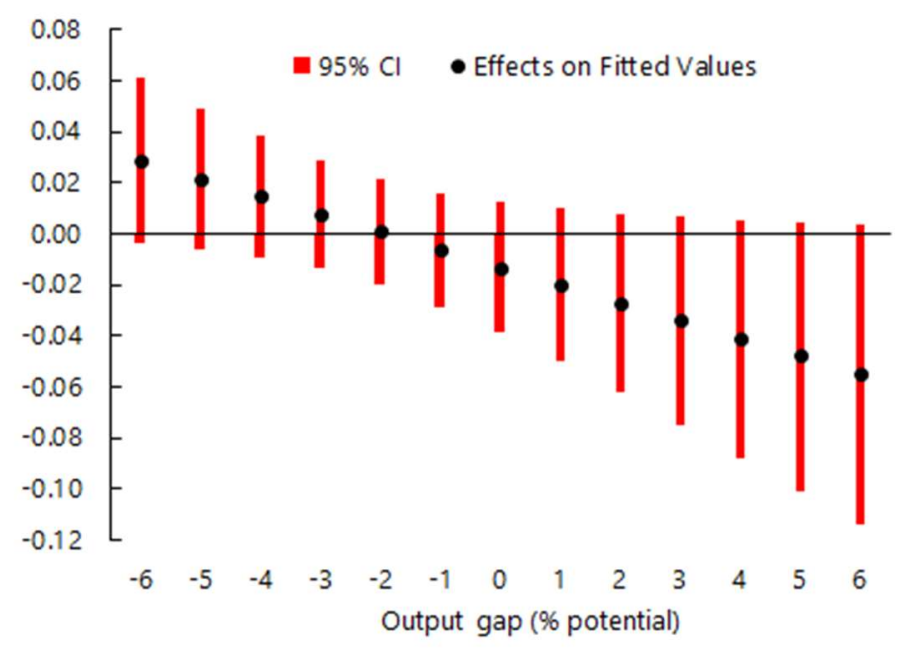

Sources: Worldscope, OECD, and IMF staff estimates. EPS = environmental policy stringency. Figure shows point estimate and $90 \%$ confidence intervals of a unit increase in market EPS on employment at discrete values of the output gap ranging from -6 to +6 .

\footnotetext{
${ }^{16}$ While the output channel is a viable explanation in the case of tighter taxes, trading schemes, and emission limits, it is unlikely to be driving the negative employments effects due to tighter feed-in tariffs (FITs), and tighter R\&D subsidies (this is observed in the disaggregated results discussed in more detail below). In these cases, the negative effects may likely be driven by the relatively greater attractiveness of investment in green sectors benefiting from the FITs and R\&D subsidies.
} 
potential GDP; Table A1 in Appendix). Note that the sample of countries experiencing extreme recessions shrinks at lower thresholds. A positive and significant effect of tightening EPS during a recession is observed for values of the output gap below the $1^{\text {st }}$ quartile, for both aggregate and market EPS (lagged 1 period), and as the threshold is lowered to the $1^{\text {st }}$ percentile, the effect size (i.e. the interaction of the dummy variable with EPS) is very sizable, although not statistically significant. ${ }^{17}$

This finding could have important implications in the current conjuncture where economic activity is weakened in many countries by the Covid-19 pandemic. It suggests that taking action on environmental policies may at the least not reduce employment; rather there could be an increase, which is somewhat surprising. An explanation for this pattern may be the inflationary impact of tighter EPS. Under contractionary conditions, tighter EPS may help to lower the real rate of interest, which may stimulate demand for example at times when policy rates are at or near the zero-lower bound.

We test this inflation channel by examining the impact of EPS on inflation CPI, PPI, and expected CPI inflation one-period ahead, in an auxiliary regression controlling for lagged inflation, the output gap, and aggregate EPS, and including country and time fixed effects (Table A2 in Appendix). These results indeed show that tighter EPS has a positive effect on inflation, statistically significant in the case of PPI inflation and 1-year ahead inflation expectations (proxied by 1-year ahead IMF inflation forecasts). Thus, there appears to be an inflationary impact of tightening EPS, which may lead to a decline in real interest rates that would stimulate demand.

Specification 2: sector proxy for emission-intensity. Taking a summary view of Specification 2 , the results lend support to employment reallocation effects between low and high-emission firms in response to tightening environmental policies, as suggested in Specification 1, most robustly with respect to aggregate and market EPS, and somewhat ambiguously for non-market EPS. Specification 2 proxies for firm level emissions with the sector of a firm. The sectors are classified into fossil fuels, high emission manufacturing, low emission manufacturing, services, construction, and transportation. Table 3 describes the composition of each sector.

Using the sample of Specification 1, we also calculate the emission-intensity of the median firm in each sector. Services, low-emission manufacturing, and construction have the lowest estimated CO2 emissions per employee, and high-emission industries and fossil fuel industries have the highest. Thus even though the sector definitions are based on a-priori judgments about exposure to tighter environmental regulations, these correspond to what would be indicated by emissions within each sector as well. The anticipated signs of tighter EPS across these sectors are negative for emission-intensive and fossil fuels-related sectors, and positive for low-emission sectors. Worldscope data does not reveal the construction sector to have high emission intensity,

${ }^{17}$ At an intermediate threshold of the $5^{\text {th }}$ percentile (output gap of about -3 percent of GDP), the effects are somewhat more ambiguous. The interaction of interest remains positive for aggregate and non-market EPS, and the size of the coefficients are larger. However, the sign on the interaction for market EPS is negative. In all cases the interaction terms are not statistically significant. 
though the effects in the construction sector would also reflect the increase in cost of some highly emission-intensive inputs such as cement. ${ }^{18}$

Table 4 shows the regression results. Similar to Specification 1, we consider aggregate, market, and non-market EPS, and the carbon taxation sub-component of market policies. The regressions include the standard determinants of labor demand, with the coefficients of those terms stable and highly significant with the expected sign (not shown). Column 1 shows the results for aggregate EPS. The coefficients on the interactions of sector dummies with aggregate EPS are as expected: fossil-fuel industries, high-emission manufacturing, construction, and transport have negative signs. The coefficient is significant for the construction sector interaction. On the other hand, the interactions of the services and the low-emission manufacturing dummy with EPS have a positive sign, although neither are statistically significant. Looking at market EPS (column 2), we observe the same pattern, and in this specification the coefficients of both construction sector and the services sector interactions are significant. In column 4 (non-market EPS) the interaction coefficients are similar as under aggregate EPS and market EPS. In the case of carbon tax (Column 3) all interaction coefficients enter with a negative sign, though none are significant. All interactions are jointly significant in columns 1, 2, and 4 (but not in column 3).

In columns $5-7$, we include a control for the output gap. The coefficient signs are as before and in addition, the interaction for high-emission manufacturing industries is now statistically significant. ${ }^{19}$ Finally, in columns $8-9$ we also include a utilities sector. While fossil fuel utilities would be expected to be highly exposed to tighter EPS, there are only a relatively small number of strictly fossil fuel-based utilities in the dataset (and it is thus not included in the baseline as a separate sector). However, allowing a broader definition of utilities (including for example multiline utilities and distribution companies), this utilities sector interaction also has the expected sign, though not statistically significant.

Net employment impact. The net effect on employment is typically small and varies by the type of policies. We use the coefficients of Specification 2 and sample employment data to conduct a quantification exercise on the net effects of policy tightening. A 1-standard deviation increase in aggregate EPS leads to a net loss of between 500-600 thousand jobs in the entire

${ }^{18}$ The scope of total emissions reported in Worldscope does not include emissions embedded in the value chain (excluding direct energy inputs). Also, the literature suggests that construction sector activity is much more emission-intensive in emerging economies (particularly China) than in advanced economies, particularly in terms of embodied emissions, which are the main source of emission in this sector (Huang and others, 2018). The predominance of advanced economy firms and absence of any firms from China in the construction sector sample may also be influencing the measured emission intensity of sector as a whole.

${ }^{19}$ The coefficient on the services sector interactions under market EPS falls just below the threshold for statistical significance. An unexpected finding is the positive (although close to zero and insignificant) coefficient on fossil fuels with respect to market EPS. This appears to be partly due to the opposing effects of different types of market-based policies. For example, the effect is negative in the case of tax policies (and only significant in case of NOX taxation).). However, the effect appears to be positive in the case of trading schemes, as well as feed-in tariffs (results available upon request).). In case of carbon trading, this may relate to the price of carbon under trading schemes. If the price of carbon is low under trading schemes, this may allow firms to maintain previous levels of output (and employment). Also given the relatively low uptake of carbon pricing policies globally, there may more scope to shift polluting activity to jurisdictions that have not implemented carbon pricing (see Ben-David and others (2020) for evidence on emission shifting by multinational firms). Even for the high-emission manufacturing sector, the effect of more stringent emissions trading policies is negative but insignificant and generally much smaller than the effect of more stringent tax policy. In the case of FITs, this likely relates to the complementarity of natural gas and renewable energy generation (where the former acts as a "backstop" for renewables-based generation). 
sample of firms across all countries (about 1 percent of the total employment in the sample). In contrast, tightening market EPS by 1 standard deviation results in a small net job increase between 13-34 thousand jobs (Figure 4). Of course, the effects will differ by country circumstances, reflecting differences in sectoral composition of employment. Figure 5 (Appendix) shows the country-wise net employment impact in terms of thousands of employees, and in percent of total country-level employment in the sample. Tighter aggregate EPS would in almost all cases lead to lower net employment, barring in the US. The average decline across all countries in the sample is about 1 percent of total employment. This is in line with the relatively small magnitude of offsetting positive effects under aggregate EPS from the low-emission sectors, as seen

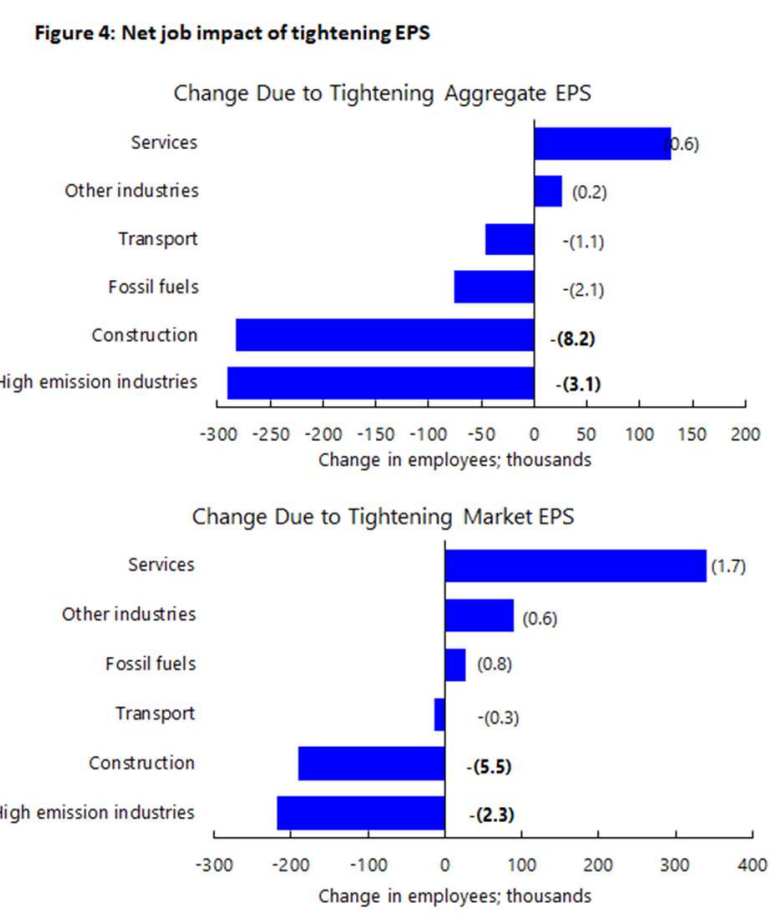

Sources: Worldscope, OECD, and IMF staff estimates. Figures in brackets show the percent change in employment from 1-standard deviation tightening of EPS. Figures in bars show change in employment in thousands, based on employment in 2015. EPS = environmental policy stringency.

in Table 4. On the other hand, tighter market EPS increases employment on net for a number of countries (by modest amounts), given the larger positive coefficient for the low-carbon sectors. For example, in the case of the US, which shows the largest net gain due to tighter market EPS, the net increase is 1.2 percent of total sample employment in 2015.

The net effects calculated here for both aggregate and market EPS likely understate the net gains/overstate the net losses, since the Worldscope sample is unevenly representative across country-sectors. In particular services sector employment for some countries is much lower in the estimation sample as compared to in national accounts. However, in almost all countries for whom Worldscope and national accounts share of service sector employment are similar, there are net gains from tighter market EPS. ${ }^{20}$

The distributional impact by wage appears to be ambiguous. At the aggregate level, median wages are lowest among the high-emission and low-emission manufacturing sectors, and highest among fossil fuel industries, followed by services, construction, and transport sectors. Thus, to the extent that services sector adds jobs, this would tend to offset distributional consequences from the loss of relatively high-wage jobs in fossil fuels, construction, and transport. It should be

\footnotetext{
${ }^{20}$ Estimation sample shares and national accounts-based shares of services sector employment are similar in the case Canada, Czech Republic, Denmark, Greece Portugal, Turkey, UK, and US. Only Portugal shows a relatively small net decline in employment from among these countries.
} 
borne in mind that these relative wages reflect listed firms, at the aggregate level, and there may variations among the larger universe of unlisted firms, and between countries. ${ }^{21}$

Overall, these results suggest that future environmental policy tightening may lead to modest job losses, and to the extent that market policies play a larger role, the effect may be quite muted if not positive, depending on the sectoral composition of employment. This muted effect is consistent with the literature on the impact of carbon taxation on employment, as described earlier.

Medium-term effects. The results from Specification 1 and 2 capture the near-term effects of tighter EPS. To look at the longer-term effects, we embed the panel GMM methodology within a Jorda local projections framework. The main conclusion from this exercise is that while market and non-market policies appear to have opposing effects on employment upon impact, over the medium term, these initial impacts tend to reverse, and fade away. Again, the employment effects are modest.

The regression equation is:

$n_{i, t+h}=\sum_{l=1}^{T} a_{k} n_{i, t-k}+b X_{i, j, t}+c_{1} E P S_{j, t}+d_{i}+d_{j}+d_{t}+\varepsilon_{i, t}$

where $h=0 \ldots 5$ is the projection horizon. Distinct from Specification 1 and 2 , the interaction terms with emissions intensity (including as proxied by the sector of a firm) and the EPS indices are excluded. The focus is on the average effect over time across all firms. As we are not restricted to firms that report $\mathrm{CO} 2$ emissions, the sample includes all firms that reported at least 10 continuous years of data on employment, wages, and capital stock, giving a sample of about 2200 firms. $^{22}$

Figure 6 shows the impulse-responses and 90\% confidence bands over a 5-year horizon in response to a 1-unit change in aggregate, market, and non-market EPS. The pattern of responses in the near-term is similar to what we find in terms of net effects in Specification 2: there is a small negative impact in the short term due to tighter aggregate EPS. Tighter market EPS has a small positive effect over the near-term, but this reverses and fades over the medium term. Tighter non-market EPS produces a noticeable decline in employment on impact. This effect becomes positive by year 2 , and then reverses by 3 years, fading out over the medium term. The lagged increase in employment demand following the initial decline in response to tighter nonmarket policies may reflect technological adjustment that helps over time to offset the higher costs of regulation, and the demand for additional resources to meet the tighter standards. The differing dynamics in response to market and non-market policies are also reflected in the response to tighter aggregate EPS: on impact, the overall effect is negative, with the relatively

${ }^{21}$ For example in the Worldscope sample, by median wage, the top 3 sectors in China are services, transport, and construction; and in India are fossil fuels, construction, and services. In both countries, manufacturing (both high-emission and low-emission) commands the lowest median wages.

${ }^{22}$ Given the unbalanced panel structure of the underlying data, one concern with this specification is that advancing forward in time may cause firms that have relatively fewer usable observations to drop out of the sample, which could bias the results. As a precaution, only firms that have at least 10 continuous years of data in the sample are included in this exercise. 
large negative impact due to tighter nonmarket policies, but over time both the reversal in non-market EPS dynamics and the positive impact of market EPS dominate.

\section{To summarize:}

Specification 1 shows that in the near term, tighter EPS clearly has a negative effect on labor demand in emissions intensive firms, and a positive effect in low-emission intensity firms. This is the case for both market and non-market policies; and is thus reflected in the aggregate EPS indicator. The point estimates show that the negative effect of non-market EPS on high-emission intensity firms is nearly twice as large as in the case of market EPS, while the positive employment effects of market versus nonmarket EPS on low-emission intensity firms are similar.

The effect of EPS appears to interact with the business cycle. Tightening EPS in weak cyclical conditions appears to increase labor demand other things equal. This somewhat surprising effect likely relates to the inflationary impact of tighter EPS, helping to lower real interest rates and stimulating demand.

Specification 2 corroborates the reallocation effect, albeit the identification is based on stronger assumptions about firms' emission intensity. As anticipated, firms in low emission sectors tend to experience employment increases while firms in high-emission sectors experience employment declines. Quantification exercises based on sample employment data suggest that market-based policies could have a positive net effect. The net employment impacts of aggregate EPS and market EPS are small overall. The sign of the net effects depends on the sectoral composition of employment. Over the medium-term, the evidence suggests that these effects are transitory, as any negative (or indeed positive) effects on firm employment seen in upon impact years tend to reverse over time and fade over the medium term.
Figure 6: Medium-term effects of EPS on employment

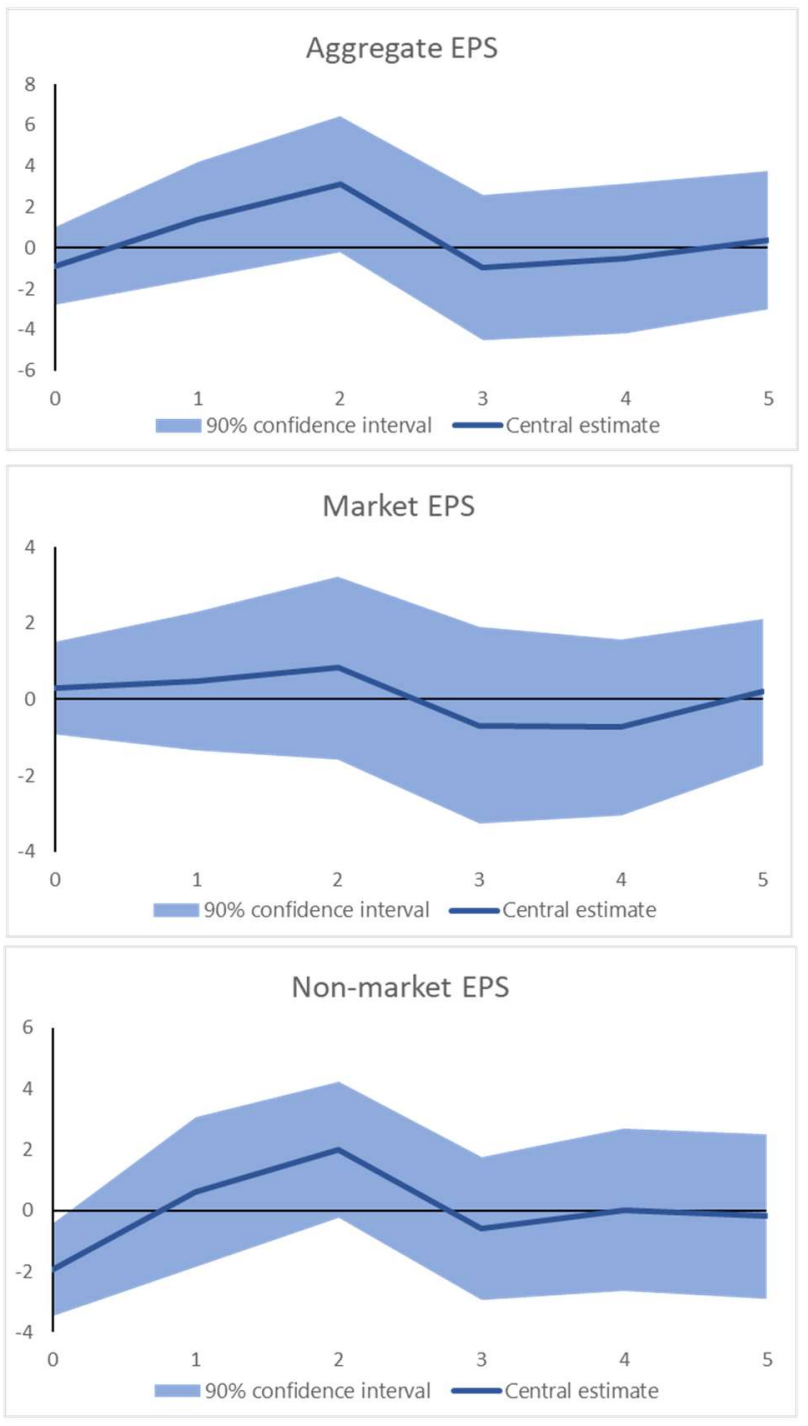

Sources: Worldscope, OECD, and IMF staff estimates. Figures show \% change in employment in response to unit change in EPS. EPS = environmental policy stringency. 
Robustness. The results of the preceding exercises are robust to a number of alternative specifications, which are discussed in this section. Time-invariant unobservable factors that drive both EPS and firm-level employment are differenced away in the estimation. Given the firm level unit of observation, and country-level variation in EPS, it is reasonable to assume that changes in EPS are exogenous to the employment decisions of any individual firm. However, it is possible that changes in labor demand may precede changes in environmental policy. Policy makers may tighten policies if firms are expanding in favorable conditions, or conversely may loosen environmental regulations to reduce costs and support firms if they are struggling. Thus, regressions including leads of policy are considered for Specification 1. Additional robustness exercises include varying the emission intensity threshold; weighted regressions to account for the unbalanced panel structure (by size of employment); robust standard errors; and winsorizing the data. We also consider regressions with real wages in place of nominal wages. These results are presented in Table 5 (Specification 1), and Table 6 (Specification 2).

For Specification 1, the results shown in Table 2A and 2B remain broadly robust. With respect to market EPS, the significant reallocation effect (i.e. significant coefficients for both the EPS indicator along, and for its interaction with the emission-intensity indicator) remains robust and statistically significant, except in the case of setting the threshold to classify high-emission firms at the $75^{\text {th }}$ percentile of the emissions-intensity distribution-which is not surprising since some substantially high emitters may in this case be classified as low-emission firms even though they experience negative employment effects. Notably, including leads in the regression does not change the qualitative results; indeed the lead of EPS is not significant in all but one specification (notes to Table 5). For aggregate and non-market EPS, we observe a significant reallocation effect on including controls for policy leads, and we observe a reallocation effect for aggregate EPS when considering real wages in place of nominal wages. The results are also robust to controlling for country-specific trends (in addition to common trends) captured by country-year dummies. Further, the results are robust to alternative numbers of lags for the instruments in the GMM specification (both for shorter and longer lags), and in these cases too the Hansen J-test cannot reject the null of instrument validity.

For Specification 2, we focus on the results for market EPS (Table 6). The sign and significance of the coefficients of the interactions of interest are broadly unchanged compared to the baseline regressions. High emissions industries and construction show negative employment effects (with the general exception of fossil fuels, though the effect in this sector turns negative when in weighted regressions). In contrast, the coefficients on the interactions with services and low emission industries remain positive; the coefficient on services is statistically significant under winsorized data, and when controlling for real wages. The quantifications of net employment impact under all these exercises remain modest, between $+/-0.4$ percent of total employment in the sample.

Disaggregated policies. Examining the impact of specific environmental policies helps to clarify the main drivers of the observed reallocation effect of tighter EPS. This is done within the framework of Specification 1, and each component policy that makes up the market and 
non-market (and the aggregate) EPS index is considered one by one, with the policies lagged one period. Table 7 shows the results. Overall, the pattern of the coefficients on the policy variable and the interaction term is consistent with the reallocation effect described above. ${ }^{23}$

Based on these results, Figure 7 shows the magnitude of the employment effects for high and low-emission intensity firms, expressed in percent change in response to a 1 -unit tightening, focusing on policies for which the interaction coefficients are jointly significant. As noted earlier, since comparisons across indices are not meaningful, we cannot simply rank employment effects based on the magnitudes of the response to a (say) 1 unit increase in each index. ${ }^{24}$ That

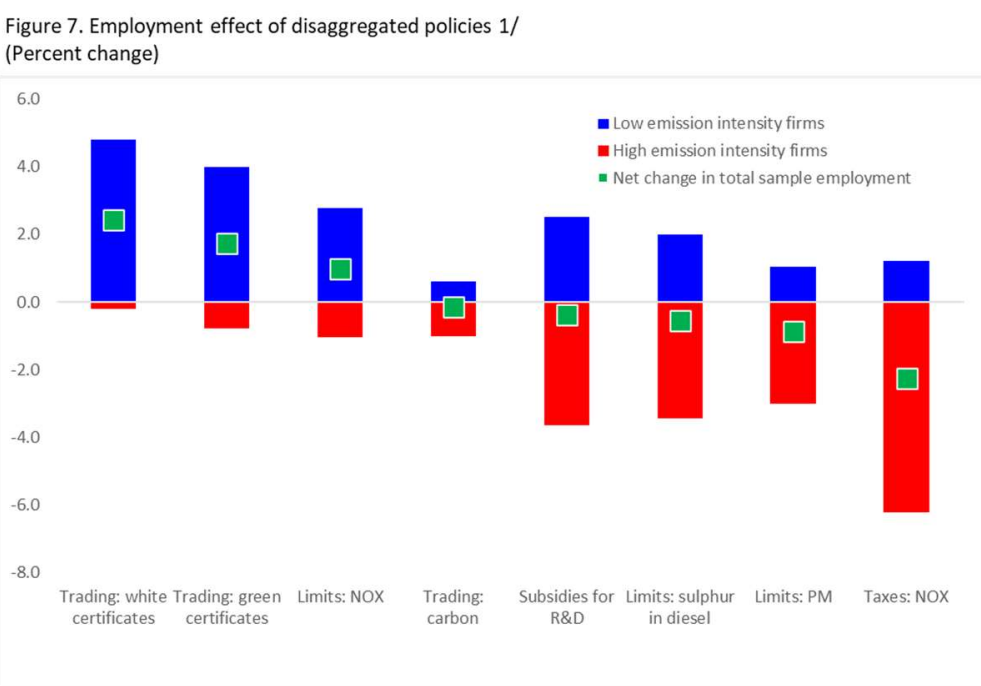

Sources: Worldscope, and IMF staff estimates. 1/ Bars show the magnitude of employment effects In response to 1-unit change in the given policy, expressed as a percent (100x the estimated semi-elasticity as shown in table 7$)$. Markers show the net employment impact, estimated on the total number of jobs in high and low-emission intensity firms in the estimation sample. said, among market policies, more stringent trading schemes (green and white certificates) lead to relatively large positive effects on low-emission intensity firms, and small negative effects on high-emission intensity firms. This suggests that the net effects could even be positive from tightening trading scheme stringency in a country with a large share of the services sector, which is typically low-emission intensity. Conversely the sizable negative impact of a tighter tax (on NOX) on employment in high-emission firms would be muted in such a country.

We can also quantify the impact of increasing an index on net employment in the sample. This can illustrate the direction of the net effect (whether positive or negative) for each policy, subject to the caveat that this is valid for the given size and distribution of high and low-emission firms in the sample. Taking the distribution of employment among high and low-emission intensity firms in the sample of Specification 1 as a whole, tightening all the jointly significant marketbased policies by 1 unit would increase employment by 1.8 percent. In contrast, tightening all jointly significant non-market policies by 1 unit would reduce employment by 0.8 percent. It is tempting to conclude that regulatory policies such as emission limits could be implemented without excessive harm to employment; but these comparisons would need further evaluation in a representative sample of firms and with policies expressed in terms of some common metric.

\footnotetext{
${ }^{23}$ These subcomponents include among market policies: taxes (aggregate, taxes on diesel, nitrous oxide (NOX), and sulphur oxides (SOX), trading (aggregate, trade in white certificates, carbon trading, trade in green certificates), feed-in tariffs (aggregate, wind, and solar); among nonmarket policies: limits (aggregate, limits on NOX, SOX, particular matter, and the sulphur content of diesel), and R\&D subsidies. The coefficients on diesel tax go the "wrong way", as seen in Table 7, but they are not jointly significant. The results are robust to inclusion of a lagged aggregate EPS term (which is never significant in any specification). Results are available upon request.

${ }^{24}$ Indeed, having such a translation would be helpful to compare employment effects of tighter policies against a given emission (reduction) target. However, the literature does not offer much guidance here as empirical evidence is limited to assessing the impact of the aggregate indices of environmental policy stringency, including the OECD EPS index, on emissions (see Wolde-Rufael and Mulat-Weldemeskel (2020), and Probst and Sauter (2015), for example).
} 
Other estimation issues. There are additional concerns of biases relating to data reporting. One is related to the relatively sparse reporting of $\mathrm{CO} 2$ emissions by firms, which raises selection bias concerns if reporting emissions is a choice made by firms. It is possible that nonreporters are predominantly high emission firms wishing to avoid market consequences of being high emitters, for instance, thereby biasing the results of Specification 1.

Looking at CO2 emission reporting by sectors as defined in Specification 2, it turns out that a higher proportion of firms in the high-emission sectors report at least one year of CO2 emissions relative to the average rate of emission reporting across all firms in all the sectors (21\%) - fossil fuel industries (26\%), transport industries (24\%), and utilities (34\%). The exception is high-emission manufacturing $(15 \%)$. This offers some reassurance that systematic non-reporting of CO2 emissions by large emitters is not a big concern for Specification 1, but it does not rule it out.

A related concern is that the sparse emission reporting may reflect systematic differences across countries. Indeed, the share of firms reporting at least one year of CO2 emissions in China, India and Indonesia is relatively much lower than in other OECD countries (3\%, 4\%, and 5\% respectively of sample firms compared to the sample average of $32 \%$ ). This could have multiple causes, which are not explored here. For Specification 1, this would imply the results are mainly reflective of the advanced OECD countries, though for Specification 2, this is less of a concern.

Another source of potential bias is survivorship, whereby firms that delist (possibly due to closure) are not included in the sample. In the context of this study, the reallocation effects could be optimistic if a significant fraction of firms engaged in high emission activities were unable to survive environmental policies and delisted from stock markets. The original dataset featured few such inactive firms (around 1 percent of the sample of more than 42,000 firms), and of these, a smaller subset report employment and wages data required for the exercise.

\section{F. Discussion and further work}

To summarize, this paper estimated the impact of environmental policy stringency on employment in the framework of a standard neoclassical labor demand curve, augmented with environmental policy variables. A novel approach of this paper is to identify the effects of environmental policy stringency on labor demand at the firm level by distinguishing between firms on the basis of their carbon emission-intensity. The main findings of this paper are that increased stringency tends to reduce labor demand in high emissions firms/sectors and increase it in low emission ones. Moreover, under contractionary conditions tighter environmental

policies may increase labor demand, other things equal. Quantification exercises suggest that net impact on employment is relatively modest and depends on the relative size of these sectors in the economy. These conclusions support similar findings in the literature. Tighter market-based policies tend to have a positive net effect while non-market policies appear to have net negative effect, depending on the sectoral composition of employment. The paper also explores disaggregated market and non-market policies. The findings are that among market policies, 
trading policies could have relatively benign employment effects as compared to tax policies, depending on the distribution of employment among high and low-emission intensity firms in the economy, while policies such as taxes on emissions may have more negative effects-though a key caveat is that policy stringency is not comparable across policies. Finally, we observe that the effects on labor demand in the near-term tend to reverse over the medium term, thus having no permanent or lasting effects.

From a policy perspective, these findings suggest that increased policy stringency at the national level needs to be accompanied by efforts to smoothen the transition of labor from high to lowemission sectors, for example through reskilling, and public expenditure in green sectors to generate green jobs. ${ }^{25}$ The finding that tightening environmental policies amid recessions does not harm employment - rather could increase employment-is somewhat counterintuitive. If this is indeed the case, it suggests that weak economic conditions may not be a deterrent to implementing tighter environmental policies from the perspective of employment. However, a more thorough understanding requires further research on what may be driving this relationship.

It is useful to note some additional caveats to this foregoing analysis, which may lay out a course for future work as well. Clearly, a more comprehensive dataset on firm-level emissions would be much more reassuring regarding the results of Specification 1, and makes the case for continued efforts to document data on emissions at the firm level. Secondly, the sample is limited to only listed firms, which could be problematic if labor demand reacts differently among unlisted firms, and particularly among informal firms in countries with large informal sectors. Again this would require a much richer dataset that reports firms' emissions more widely than captured in this paper. OECD (2020) applies country-sector level emissions as a proxy in Orbis data, but as noted earlier, this could obscure firm-level heterogeneity in emissions within broadly defined sectors. Thirdly, richer data on the degree to which firms are subjected to competition in their markets would be useful, allowing us to test to what extent firms in more competitive conditions are more sensitive to climate policies than firms in relatively protected settings. Finally, additional work to express disaggregated policies in comparable emission-related units may be very useful for policy makers to compare employment effects across policies, and to estimate the potential employment effects of future policies to mitigate climate change.

${ }^{25}$ This may yet leave workers employed in high emission sectors vulnerable, thus necessitating income support policies for such workers. In the case of carbon taxation, that could be achieved by recycling carbon tax revenues among affected households. 


\section{References}

Ben-David, I., S. Kleimeier, and M. Viehs, 2020, "Exporting pollution: where do multinational firms emit CO2?”, NBER Working Paper 25063.

Deschenes, Olivier, 2010, “Climate policy and labor markets,” NBER Working Paper 16111.

Deschenes, Olivier, 2018, "Environmental regulations and labor markets," IZA World of Labor 2018

Eggertson, G., 2012, “Was the New Deal contractionary?”, American Economic Review 102(1)

Greenstone, M., 2002, “The Impacts of Environmental Regulations on Industrial Activity:

Evidence from the 1970 and 1977 Clean Air Act Amendments and the Census of

Manufactures," Journal of Political Economy 110.

IMF, 2019, "How to Mitigate Climate Change," Chapter 3 in Fiscal Monitor, October 2019, Washington DC.

, 2020, "Mitigating Climate Change - Growth and Distribution Friendly Strategies," Chapter 3 in World Economic Outlook, October 2020, Washington D.C.

, 2020, "Sectoral Policies for Climate Change Mitigation in the EU," IMF Departmental Paper (European Department), Washington D.C.

Hepburn, C., 2006, "Regulation by prices, quantities or both: a review of instrument choices," Oxford Review of Economic Policy 22(2).

Huang, L., G. Krigsvoll, F. Johansen, Y. Liu, X. Zhang. 2018, “Carbon emissions of global construction sector," Renewable and Sustainable Energy Reviews 81.

Kahn, M.E., 1997, "Particulate pollution trends in the United States," Regional Science and Urban Economics 27

Liu, M., R. Shadbegian, and B. Zhang, 2017, "Does environmental regulation affect labor demand in China? Evidence from the textile printing and dyeing industry," Journal of Environmental Economics and Management 86.

Metcalf, G.E., and J.H. Stock, 2020, "Measuring the Macroeconomic Impact of Carbon Taxes," AEA papers and Proceedings 110

OECD, 2014, "Measuring environmental policy stringency in OECD countries - a composite index approach,” Economic Department Working Papers No. 1177, Paris. , 2020, "Measuring and assessing the effects of environmental policy uncertainty," ECO/CPE/WP1/2020(22), Paris.

Probst, M., and C. Sauter, 2015, "CO2 Emissions and Greenhouse Gas Policy Stringency - An Empirical Assessment,” Working Paper 15-03, IRENE. 
Van Reenen, J., 1997, "Employment and Technological Innovation: Evidence from U.K. Manufacturing Firms,” Journal of Labor Economics, 15(2).

Yip, Chi Man, 2018, “On the labor market consequences of environmental taxes," Journal of Environmental Economics and Management 89.

Yamazaki, A., 2017, “Jobs and climate policy: Evidence from British Columbia's revenue-neutral carbon tax," Journal of Environmental Economics and Management 83.

Weitzman, M., 1974, “Prices vs Quantities,” Review of Economic Studies, October, 41(4).

Wolde-Rufael, Y., and E. Mulat-Weldemeskel, 2021, "Do environmental taxes and environmental stringency policies reduce CO2 emissions? Evidence from 7 emerging economies," Environmental Science and Pollution Research (2021) 


\section{Tables}

Table 1: Summary statistics

\begin{tabular}{|c|c|c|}
\hline Variable & Mean & Std. Dev. \\
\hline \multicolumn{3}{|c|}{ Sample 1: interaction with high/low $\mathrm{CO} 2$} \\
\hline Aggregate EPS & 2.5 & 0.9 \\
\hline Market EPS & 1.9 & 1.0 \\
\hline EPS: CO2 Tax & 0.1 & 0.9 \\
\hline Non-Market EPS & 3.1 & 1.2 \\
\hline log employees & 9.6 & 1.5 \\
\hline log capital stock & 14.5 & 1.8 \\
\hline log wage & 3.9 & 0.8 \\
\hline $\log r$ & 0.0 & 0.1 \\
\hline Output gap & 0.0 & 2.2 \\
\hline $\log \mathrm{CO} 2$ emissions & 8.9 & 10.0 \\
\hline \multicolumn{3}{|c|}{ Sample 2: interaction with sector dummies } \\
\hline Aggregate EPS & 2.2 & 0.9 \\
\hline Market EPS & 1.7 & 0.9 \\
\hline EPS: CO2 Tax & 0.1 & 0.8 \\
\hline Non-Market EPS & 2.7 & 1.3 \\
\hline log employees & 7.8 & 1.9 \\
\hline log capital stock & 12.2 & 2.2 \\
\hline log wage & 3.2 & 1.2 \\
\hline $\log r$ & 0.0 & 0.1 \\
\hline Output gap & -0.2 & 2.0 \\
\hline
\end{tabular}

Notes: Estimation sample 1 includes 670 firms, from 30 countries over 2000-2015. Sample 2 consists of 5305 firms, covering 31 countries over 2000-2015. Capital stock is calculated as sum of machinery and building stock in $\$ 000$ deflated by corresponding capital goods price deflators from Penn World Tables. Wages are calculated as total staff costs (in \$ 000 ) divided by total employees. Rental rate $r$ is log of the price of capital services at the country level, from Penn World Tables. CO2 emissions are measured in tonnes.

\section{Table 3: Sector descriptions and codes}

\begin{tabular}{|c|c|c|c|}
\hline Sector name & Description & Worldscope codes & Emissions 1/ \\
\hline Fossil fuels & $\begin{array}{l}\text { Industries related to coal, oil and gas exploration, } \\
\text { mining, refining, and marketing. }\end{array}$ & 5010 & 1281 \\
\hline High emission manufacturing & $\begin{array}{l}\text { Manufacturing in chemicals, metals and minerals, } \\
\text { paper and packaging, and food and beverages } \\
\text { industries }\end{array}$ & $5110,5120,5130,5410$ & 1101 \\
\hline Other (low emission) manufacturing & $\begin{array}{l}\text { Manufacturing in renewable energy, aerospace and } \\
\text { defense, industrial machinery and equipment, ship- } \\
\text { building, consumer durables and non-durables, IT } \\
\text { equipment }\end{array}$ & $\begin{array}{l}\text { 5020, 5030, 5210, 5230, 5310, } 5320 \\
\text { (excl. home building activities), } 5420 \\
\text { (excl. personal services) }\end{array}$ & 189 \\
\hline Services & $\begin{array}{l}\text { Industrial and commercial services, consumer cyclical } \\
\text { services (hotels and enterntainment, media and } \\
\text { publishing), retail services, personal services, financial, } \\
\text { insurance, and real estate services, IT services. }\end{array}$ & $\begin{array}{l}5220 \text { (excl. commercial and } \\
\text { engineering construction), 5330, 5340, } \\
5420 \text { (excl. personal products), 5430, } \\
5510,5560,5530,5540,5550,5610\end{array}$ & 126 \\
\hline Construction & $\begin{array}{l}\text { Commericial and industrial construction and } \\
\text { engineering, home building }\end{array}$ & 522010,53203010 & 212 \\
\hline Transport & $\begin{array}{l}\text { Transport by air, sea, and land; transport infrastructure } \\
\text { operators }\end{array}$ & 5240 & 973 \\
\hline Utilities & $\begin{array}{l}\text { Electrical fossil fuel-based utilities and electric utilities } \\
\text { not elsewhere classified, including independent power } \\
\text { producers }\end{array}$ & $\begin{array}{l}\text { 5910101010, 5910101012, 5910102010, } \\
5910102011\end{array}$ & 13300 \\
\hline
\end{tabular}

Source: Worldscope Database - Data Definitions Guide (Issue 15). 1/ Median CO2 emissions/employee (in thousand tons), 2015.

\section{CInternational Monetary Fund. Not for Redistribution}


Table 2A: CO2 emission intensity and labor demand (contemporaneous policies)

\begin{tabular}{|c|c|c|c|c|c|c|c|c|c|}
\hline & 1 & 2 & 3 & 4 & 5 & 6 & 7 & 8 & 9 \\
\hline $\begin{array}{l}\text { EPS Indicator } \\
\text { Dependent variable }\end{array}$ & $\log N$ & $\begin{array}{l}\text { Agg EPS } \\
\log N\end{array}$ & $\begin{array}{l}\text { Mkt EPS } \\
\log N\end{array}$ & $\begin{array}{c}\text { CO2 Tax } \\
\log N\end{array}$ & $\begin{array}{c}\text { Non-Mkt } \\
\text { Log N }\end{array}$ & $\begin{array}{l}\text { Agg EPS } \\
\log N\end{array}$ & $\begin{array}{l}\text { Mkt EPS } \\
\log N\end{array}$ & $\begin{array}{c}\text { CO2 Tax } \\
\log N\end{array}$ & $\begin{array}{c}\text { Non-Mkt } \\
\log N \\
\end{array}$ \\
\hline $\log N(t-1)$ & $0.573^{\star \star \star}$ & $0.560^{\star \star \star}$ & $0.566^{\star \star \star}$ & $0.565^{\star \star \star}$ & $0.555^{\star \star *}$ & $0.556^{\star \star \star}$ & $0.561^{\star \star \star}$ & $0.562^{\star * *}$ & $0.552^{* \star *}$ \\
\hline $\log N(t-2)$ & $-0.142^{\star \star \star}$ & $-0.144^{\star \star \star}$ & $-0.144^{\star * *}$ & $-0.143^{* * *}$ & $-0.144^{\star \star \star}$ & $-0.141^{\star \star \star}$ & $-0.142^{\star \star \star}$ & $-0.141^{\star \star \star}$ & $-0.140^{\star \star \star *}$ \\
\hline log capital stock & $0.276^{\star *}$ & $0.266^{\star *}$ & $0.268^{* *}$ & $0.275^{\star *}$ & $0.263^{\star *}$ & $0.266^{* *}$ & $0.272^{* *}$ & $0.273^{* *}$ & $0.262^{\star \star}$ \\
\hline log wages & $-0.260^{\star *}$ & $-0.252^{* \star}$ & $-0.252^{\star *}$ & $-0.254^{\star *}$ & $-0.238^{*}$ & $-0.256^{\star *}$ & $-0.255^{\star \star}$ & $-0.259 * *$ & $-0.256^{\star *}$ \\
\hline $\log r$ & $0.308^{\star \star}$ & $0.292^{\star \star \star}$ & $0.301^{\text {** }}$ & $0.308^{* *}$ & $0.300^{* \star *}$ & $0.256^{* *}$ & $0.275^{\star \star}$ & $0.284^{\star *}$ & $0.247^{\star *}$ \\
\hline EPS & & 0.0270 & 0.0224 & 0.0408 & $0.0355^{*}$ & 0.0243 & 0.0194 & 0.0364 & 0.0282 \\
\hline EPS X (High CO2=1) & & $-0.0785^{\star}$ & -0.0561 & -0.0948 & $-0.0760^{\star *}$ & $-0.0799 *$ & -0.0560 & -0.0981 & $-0.0773^{* *}$ \\
\hline Output gap & & & & & & 0.0151 & $0.0147^{\star \star}$ & 0.00367 & 0.0128 \\
\hline Output gap X EPS & & & & & & -0.00489 & $-0.00697^{* *}$ & -0.00995 & -0.00286 \\
\hline Firm fixed effects & Yes & Yes & Yes & Yes & Yes & Yes & Yes & Yes & Yes \\
\hline Year effects & Yes & Yes & Yes & Yes & Yes & Yes & Yes & Yes & Yes \\
\hline GMM instrumented & $\operatorname{lag} n, k, w, r$ & $\operatorname{lag} n, k, w$ & $\operatorname{lag} n, k, w, r$ & lag $n, k, w, r$ & lag $n, k, w, r$ & lag $n, k, w, r$ & $\operatorname{lag} n, k, w, r$ & lag $n, k, w, r$ & lag $n, k, w, r$ \\
\hline Hansen J-test (p-val) & 0.03 & 0.14 & 0.13 & 0.12 & 0.20 & 0.12 & 0.12 & 0.10 & 0.13 \\
\hline Observations & 6,415 & 5,991 & 5,991 & 5,991 & 5,991 & 5,991 & 5,991 & 5,991 & 5,991 \\
\hline Number of panelid & 674 & 670 & 670 & 670 & 670 & 670 & 670 & 670 & 670 \\
\hline
\end{tabular}

Note: ${ }^{* *} \mathrm{p}<0.01,{ }^{* *} \mathrm{p}<0.05,{ }^{*} \mathrm{p}<0.1$. "EPS" in the list of explanatory variables refers to Aggregate EPS in column 2 and 6; Market EPS in column 3 and 7; Carbon taxes in column 4 and 8; and Non-market EPS in column 5 and 9. All regressions include panel and year fixed effects. In columns 2-9, wages, capital, and rental rate are GMM-instrumented with lags. The Hansen J-test cannot reject instrument validity at $1 \%$ in column 1 , at $10 \%$ in columns $2-9$. $N=$ employees.

Table 2B: CO2 emission intensity and labor demand (lagged policies)

\begin{tabular}{|c|c|c|c|c|c|c|c|c|c|}
\hline \multirow{3}{*}{$\begin{array}{l}\text { EPS Indicator } \\
\text { Dependent variable }\end{array}$} & \multirow[b]{3}{*}{$\log N$} & $\begin{array}{ll}1 \quad 2 \\
1\end{array}$ & 3 & $\begin{array}{ll}3 \quad 4\end{array}$ & $\begin{array}{ll}4 & 5\end{array}$ & 6 & $\begin{array}{ll}5 & 7\end{array}$ & $\begin{array}{ll}7 & 8\end{array}$ & \multirow{2}{*}{$\begin{array}{r}{ }^{9} \\
\text { Non-Mkt }\end{array}$} \\
\hline & & Agg EPS & Mkt EPS & CO2 Tax & Non-Mkt & Agg EPS & Mkt EPS & CO2 Tax & \\
\hline & & $\log N$ & $\log N$ & $\log N$ & $\log N$ & $\log N$ & $\log N$ & $\log N$ & $\log N$ \\
\hline $\log N(t-1)$ & $0.573^{\star * *}$ & $0.562^{* * *}$ & $0.564^{\star \star \star}$ & $0.567^{\star \star \star}$ & $0.559^{* * *}$ & $0.559^{* \star *}$ & $0.561^{\star * *}$ & $0.564^{\star * *}$ & $0.557^{\star \star \star}$ \\
\hline $\log N(t-2)$ & $-0.142^{* \star \star}$ & $-0.149 * \star \star$ & $-0.147^{\star \star \star}$ & $-0.148^{\star \star \star}$ & $-0.152^{\star \star \star}$ & $-0.147^{\star \star \star}$ & $-0.145^{\star \star \star}$ & $-0.144^{\star \star \star}$ & $-0.150 * \star \star$ \\
\hline log capital stock & $0.276^{\star \star}$ & $0.274^{\star \star \star}$ & $0.276^{\star \star \star}$ & $0.287^{\star \star}$ & $0.275^{\star \star \star}$ & $0.273^{\star \star \star}$ & $0.277^{\star \star}$ & $0.283^{* *}$ & $0.272^{\star \star \star}$ \\
\hline log wages & -0.260 ** & $-0.252^{\star \star}$ & $-0.253^{\star *}$ & $-0.256^{\star \star}$ & $-0.252^{\star \star}$ & $-0.256^{\star \star}$ & $-0.256^{\star \star}$ & $-0.262^{\star \star}$ & $-0.256^{\star \star}$ \\
\hline $\log r$ & $0.308^{\star \star}$ & $0.289 * *$ & $0.300^{* \star}$ & $0.305^{\star \star}$ & $0.279 * *$ & $0.249 * *$ & $0.261^{\star *}$ & $0.279 * *$ & $0.228^{*}$ \\
\hline EPS & & 0.0341 & $0.0357^{\star *}$ & 0.0770 & 0.0283 & 0.0329 & $0.0329 *$ & 0.0725 & 0.0237 \\
\hline EPS X $($ High CO2 $=1)$ & & $-0.0858^{\star *}$ & $-0.0673^{\star *}$ & -0.156 & $-0.0775^{\star \star}$ & $-0.0866^{\star *}$ & $-0.0665^{\star \star}$ & -0.158 & $-0.0780^{\star \star}$ \\
\hline Output gap & & & & & & 0.0124 & 0.0147 & 0.00419 & 0.00872 \\
\hline Output gap X EPS & & & & & & -0.00360 & -0.00634 & -0.0123 & -0.00126 \\
\hline Firm fixed effects & Yes & Yes & Yes & Yes & Yes & Yes & Yes & Yes & Yes \\
\hline Year effects & Yes & Yes & Yes & Yes & Yes & Yes & Yes & Yes & Yes \\
\hline GMM instrumented & $\operatorname{lag} n, k, w$ & $r \operatorname{lag} n, k, w, r$ & $\operatorname{lag} n, k, w, r$ & $r \operatorname{lag} n, k, w, r$ & $r \operatorname{lag} n, k, w_{t}$ & $\operatorname{lag} n, k, w, r$ & $r \operatorname{lag} n, k, w, r$ & $r \operatorname{lag} n, k, w, r$ & $\operatorname{lag} n, k, w, r$ \\
\hline Hansen J-test ( $p$-val) & 0.03 & 0.06 & 0.07 & 0.07 & 0.07 & 0.04 & 0.07 & 0.08 & 0.04 \\
\hline Observations & 6,415 & 6,138 & 6,138 & 6,138 & 6,138 & 6,138 & 6,138 & 6,138 & 6,138 \\
\hline Number of panelid & 674 & 671 & 671 & 671 & 671 & 671 & 671 & 671 & 671 \\
\hline
\end{tabular}

Note: ${ }^{* \star *} p<0.01,{ }^{* \star} p<0.05,{ }^{*} p<0.1$. "EPS" in the list of explanatory variables refers to Aggregate EPS in column 2 and 6; Market EPS in column 3 and 7; Carbon taxes in column 4 and 8; and Non-market EPS in column 5 and 9 . All regressions include panel and year fixed effects. In columns 2-9, wages, capital, and rental rate are GMM-instrumented with lags. The Hansen J-test cannot reject instrument validity at $1 \%$ in column 1 , at $10 \%$ in columns $2-9$. $N=$ employees. 
Table 4: Impact of tigher EPS on labor demand across sectors

\begin{tabular}{|c|c|c|c|c|c|c|c|c|c|}
\hline & 1 & 2 & 3 & 4 & 5 & 6 & 7 & 8 & 9 \\
\hline EPS Indicator & Agg EPS & Mkt EPS & CO2 Tax & Non-Mkt EPS & Agg EPS & Mkt EPS & Non-Mkt EPS & Agg EPS & Mkt EPS \\
\hline Dependent variable & $\log N$ & $\log N$ & $\log N$ & $\log N$ & $\log N$ & $\log N$ & $\log N$ & $\log N$ & $\log N$ \\
\hline Fossil Fuels X EPS & -0.0181 & 0.00821 & -0.723 & -0.0345 & -0.0234 & 0.00980 & -0.0380 & -0.0243 & 0.0104 \\
\hline High CO2 Industries X EPS & -0.0228 & -0.0257 & -0.00432 & -0.0212 & $-0.0346^{\star}$ & $-0.0295^{\star}$ & $-0.0293^{\star *}$ & $-0.0361^{*}$ & $-0.0292^{*}$ \\
\hline Other Industries X EPS & 0.0155 & 0.0131 & -0.00534 & 0.00565 & 0.00189 & 0.00726 & -0.00436 & 0.000557 & 0.00673 \\
\hline Services $X$ EPS & 0.0174 & $0.0225^{*}$ & -0.00792 & 0.00517 & 0.00697 & 0.0208 & -0.00344 & 0.00545 & 0.0201 \\
\hline Construction $X$ EPS & $-0.0836^{\star \star \star}$ & $-0.0693^{\star \star}$ & -0.140 & $-0.0717^{\star \star \star}$ & $-0.0906^{\star \star \star}$ & $-0.0695^{\star *}$ & $-0.0766^{\star \star \star}$ & $-0.0919 * \star \star$ & $-0.0706^{\star *}$ \\
\hline Transport X EPS & -0.00319 & -0.00696 & -0.0188 & -0.00631 & -0.0118 & -0.00417 & -0.0148 & -0.0115 & -0.000983 \\
\hline FF Utilities X EPS & & & & & & & & -0.0226 & -0.0266 \\
\hline Output gap & & & & & $0.00806^{\star \star *}$ & $0.00920^{\star \star \star}$ & $0.00838^{\star \star \star}$ & $0.00857^{\star \star \star}$ & $0.00967^{\star \star \star}$ \\
\hline Joint significant & 0.05 & 0.06 & 0.65 & 0.05 & 0.05 & 0.07 & 0.03 & 0.07 & 0.10 \\
\hline Observations & 25,631 & 25,631 & 25,637 & 25,637 & 25,631 & 25,631 & 25,631 & 26,072 & 26,072 \\
\hline Number of firms & 5,305 & 5,305 & 5,305 & 5,305 & 5,305 & 5,305 & 5,305 & 5,384 & 5,384 \\
\hline
\end{tabular}

Note: ${ }^{* *} p<0.01,{ }^{* *} p<0.05,{ }^{*} p<0.1$. "EPS" in the list of explanatory variables refers to Aggregate EPS in column 2; Market EPS in column 3; Carbon taxes in column 4; and Non-market EPS in column 5 and 8; Aggregate EPS in column 6 and 9; and Market EPS in column 7 and 10 . All regressions include panel and year fixed effects. Wages, capital, and rental rate are GMM-instrumented with lags. The interactions span the entire sample of firms included in the regressions (i.e. firms not included in any of the sectors defined above are dropped). $\mathrm{N}=$ employees 
Table 5: Robustness checks (Specification 1)

\section{Lagged policy}

EPS:

Aggregate Market Non-market

\section{Higher emission threshold}

EPS

EPS X High Emission

0.00833

(0.0173)

$-0.0752^{*}$

(0.0416)

2. Including leads

EPS

EPS $X$ High Emission

$\begin{array}{ccc}0.0502^{* *} & 0.0345^{\star *} & 0.0517^{\star *} \\ (0.0253) & (0.0161) & (0.0262) \\ -0.0991^{* \star} & -0.0597^{\star *} & -0.109^{* *} \\ (0.0395) & (0.0277) & (0.0439)\end{array}$

3. Weighted regression

EPS

EPS X High Emission

4. Robust standard errors

EPS

EPS X High Emission

$\begin{array}{ccc}0.0368 & 0.0389^{\star *} & 0.0321 \\ (0.0230) & (0.0171) & (0.0229) \\ -0.0980^{\star * \star} & -0.0743^{\star *} & -0.0911^{* *} \\ (0.0379) & (0.0303) & (0.0377)\end{array}$

\subsection{5}

(0.0229)

$-0.0858^{\star *}$

(0.0381)

$0.0360^{* *}$

(0.0172)

$-0.0670^{* *}$

(0.0310)

\subsection{2}

(0.0228)

$-0.0777^{* *}$

(0.0370)

5. Winsorized

EPS

EPS X High Emission

$$
0.0317
$$

$(0.0231)$

0.0339 *

(0.0173)

$-0.0817^{\star \star}$

$-0.0641^{\text {** }}$

(0.0387)

$(0.0314)$

\subsection{1}

(0.0231)

$-0.0736^{*}$

(0.0377)

\section{Real wages}

EPS

EPS X High Emission

$\begin{array}{ccc}0.0421^{*} & 0.0380^{* *} & 0.0368 \\ (0.0246) & (0.0181) & (0.0245) \\ -0.0839^{\star *} & -0.0669^{\star *} & -0.0778^{\star \star} \\ (0.0392) & (0.0323) & (0.0380)\end{array}$

7. Country-year dummies

EPS

EPS X High Emission

$\begin{array}{ccc}0.141 & 0.161^{\star *} & -0.0708 \\ (0.128) & (0.0707) & (0.0633) \\ -0.0861^{\star *} & -0.0690^{\star} & -0.0814^{\star} \\ (0.0431) & (0.0352) & (0.0415)\end{array}$

\begin{tabular}{ccc}
\multicolumn{3}{c}{ Contemporaneous policy } \\
\hline Aggregate & Market & Non-market \\
\hline & & \\
0.00836 & 0.0140 & 0.0114 \\
$(0.0190)$ & $(0.0115)$ & $(0.0163)$ \\
$-0.104^{*}$ & $-0.0956^{*}$ & $-0.0763^{*}$ \\
$(0.0563)$ & $(0.0509)$ & $(0.0462)$
\end{tabular}

$\begin{array}{ccc}0.0359 & 0.0243 & 0.0228 \\ (0.0253) & (0.0185) & (0.0252) \\ -0.0802 & -0.0523 & -0.0652 \\ (0.0545) & (0.0418) & (0.0418)\end{array}$

0.0271

$0.0268 \quad 0.0348^{*}$

(0.0227)

(0.0180)

$-0.0704^{*}$

(0.0210)

-0.0932 **

(0.0382)

-0.0850 **

(0.0443)

(0.0380)

$\begin{array}{ccc}0.0270 & 0.0224 & 0.0355^{\star} \\ (0.0229) & (0.0180) & (0.0210) \\ -0.0785^{*} & -0.0561 & -0.0760^{\star *} \\ (0.0441) & (0.0376) & (0.0381)\end{array}$

0.0245

$0.0218 \quad 0.0323$

$(0.0225)$

(0.0181)

(0.0207)

$-0.0750^{*}$

$-0.0557$

$-0.0706^{*}$

(0.0450)

(0.0388)

(0.0386)

$\begin{array}{ccc}0.0338 & 0.0232 & 0.0449 * * \\ (0.0231) & (0.0188) & (0.0219) \\ -0.0766^{*} & -0.0568 & -0.0750^{*} \\ (0.0459) & (0.0400) & (0.0394)\end{array}$

0.0711

0.00811

0.0460

$(0.111)$

(0.0830)

$(0.0760)$

$\begin{array}{lll}-0.0747 & -0.0514 & -0.0773 \text { * }\end{array}$

$(0.0472) \quad(0.0403) \quad(0.0427)$

Notes: Robust standard errors in parentheses. ${ }^{* *} p<0.01,{ }^{* *} p<0.05$, ${ }^{*} p<0.1$

Columns 1 - 3 show results for interactions with lagged EPS. Columns $4-6$ show interactions with contemporaneous EPS. The column title indicates the particular EPS indicator. (1) the cutoff for high emission is set at the 75th percentile of the $\mathrm{CO} 2$ emission-to-employment ratio for a given country-year. (2) regressions include the interaction with 1 year leads of the policy indicator (those coefficients are not reported, always insignificant for interactions with leads, except in the case of non-market EPS and lagged policy). (3) Regressions are weighted by employment. (4) Standard errors are clustered at the firm level. (5) Observations are winsorized at the $95 \%$ level. (6) Wages deflated by CPI. 
Table 7: Impact of specific market and non-market policies

\begin{tabular}{|c|c|c|c|c|c|c|c|c|c|c|c|c|c|}
\hline \multirow[t]{2}{*}{ Policy type: } & \multicolumn{3}{|c|}{ Taxes } & \multicolumn{3}{|c|}{ Trading schemes } & \multicolumn{2}{|c|}{ FITs } & \multicolumn{4}{|c|}{ Emission limits } & \multirow{2}{*}{$\begin{array}{c}\text { Subsidies } \\
13\end{array}$} \\
\hline & 1 & 2 & 3 & 4 & 5 & 6 & 7 & 8 & 9 & 10 & 11 & 12 & \\
\hline $\begin{array}{l}\text { EPS Indicator } \\
\text { Dependent variable }\end{array}$ & $\begin{array}{l}\text { Diesel } \\
\text { Log N } \\
\end{array}$ & $\begin{array}{l}\text { NOX } \\
\text { Log N } \\
\end{array}$ & $\begin{array}{c}\text { SOX } \\
\text { Log } N \\
\end{array}$ & $\begin{array}{c}\text { Green } \\
\text { certificate } \\
\text { Log N } \\
\end{array}$ & $\begin{array}{l}\text { Carbon } \\
\log N\end{array}$ & $\begin{array}{c}\text { White } \\
\text { certificate } \\
\text { Log N } \\
\end{array}$ & $\begin{array}{l}\text { Wind } \\
\text { Log N }\end{array}$ & $\begin{array}{l}\text { Solar } \\
\text { Log N }\end{array}$ & $\begin{array}{r}\text { NOX } \\
\text { Log N } \\
\end{array}$ & $\begin{array}{c}\text { SOX } \\
\text { Log } N \\
\end{array}$ & $\begin{array}{c}\text { PM } \\
\text { Log N } \\
\end{array}$ & $\begin{array}{c}\text { Sulphur in } \\
\text { diesel } \\
\text { Log } N \\
\end{array}$ & $\begin{array}{l}\text { R\&D } \\
\log N \\
\end{array}$ \\
\hline $\log N(t-1)$ & $0.561^{\star \star \star}$ & $0.560^{\star \star \star}$ & $0.569^{* * *}$ & $0.556^{\star \star \star}$ & $0.564^{\star \star \star}$ & $0.556^{\star \star \star}$ & $0.567^{\star \star \star}$ & $0.563^{\star \star \star}$ & $0.558^{\star \star \star}$ & $0.558^{\star \star \star}$ & 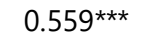 & $0.562^{\star \star \star}$ & $0.563^{* \star *}$ \\
\hline $\log N(t-2)$ & $-0.143^{\star \star \star}$ & $-0.145^{\star \star \star}$ & $-0.145^{\star \star \star}$ & $-0.144^{\star \star \star}$ & $-0.145^{\star \star \star}$ & $-0.149^{* * *}$ & $-0.145^{\star \star \star}$ & $-0.148^{\star \star \star}$ & $-0.147^{\star \star \star}$ & $-0.148^{\star \star \star}$ & $-0.148^{\star \star \star}$ & $-0.146^{\star \star *}$ & $-0.149^{* \star *}$ \\
\hline log capital stock & $0.283^{* * *}$ & $0.274^{\star *}$ & $0.282^{\star *}$ & $0.283^{\star * *}$ & $0.278^{\star *}$ & $0.280^{* *}$ & $0.277^{\star \star *}$ & $0.281^{\star \star *}$ & $0.271^{\star * *}$ & $0.274^{\star * \star}$ & $0.283^{* * *}$ & $0.272^{\star * *}$ & $0.276^{\star *}$ \\
\hline log wages & $-0.257^{\star \star}$ & $-0.259^{\star \star}$ & $-0.259 * *$ & $-0.261^{\star *}$ & $-0.257^{\star \star}$ & $-0.252^{\star *}$ & $-0.257^{\star \star}$ & $-0.253^{\star *}$ & $-0.255^{\star \star}$ & $-0.254^{\star \star}$ & $-0.261^{\star \star}$ & $-0.254^{\star \star}$ & $-0.258^{\star *}$ \\
\hline $\log r$ & $0.309^{* *}$ & $0.296^{\star \star}$ & $0.306^{\star \star}$ & $0.340^{* *}$ & $0.299^{* \star}$ & $0.351^{\star \star \star}$ & $0.299 * \star$ & $0.308^{\star *}$ & $0.323^{* *}$ & $0.312^{\star *}$ & $0.296^{\star \star}$ & $0.299 * \star$ & $0.292^{\star *}$ \\
\hline EPS & -0.0186 & 0.0123 & 0.0210 & $0.0399 * *$ & 0.00618 & $0.0479 * \star$ & 0.00718 & $0.0147^{*}$ & $0.0279 * \star$ & $0.0233^{* *}$ & 0.0105 & 0.0199 & 0.0253 \\
\hline EPS X $($ High CO2=1) & $0.0456^{\star}$ & -0.0746 & -0.0443 & $-0.0478^{*}$ & $-0.0163^{\star *}$ & $-0.0500^{\star}$ & -0.00772 & $-0.0310^{*}$ & $-0.0382^{*}$ & $-0.0371^{*}$ & $-0.0407^{\star \star}$ & $-0.0543^{* *}$ & $-0.0618^{*}$ \\
\hline Firm fixed effects & Yes & Yes & Yes & Yes & Yes & Yes & Yes & Yes & Yes & Yes & Yes & Yes & Yes \\
\hline Year effects & Yes & Yes & Yes & Yes & Yes & Yes & Yes & Yes & Yes & Yes & Yes & Yes & Yes \\
\hline GMM instrumented & lag $n, k, w, r$ & $\operatorname{lag} n, k, w, r$ & $\operatorname{lag} n, k, w, r$ & lag $n, k, w, r$ & $\operatorname{lag} n, k, w, r$ & lag $n, k, w, r$ & $\operatorname{lag} n, k, w, r$ & lag $n, k, w, r$ & lag $n, k, w, r$ & lag $n, k, w, r$ & lag $n, k, w, r$ & lag $n, k, w, r$ & $\operatorname{lag} n, k, w, r$ \\
\hline Hansen J-test (p-val) & 0.08 & 0.09 & 0.09 & 0.14 & 0.11 & 0.09 & 0.04 & 0.06 & 0.08 & 0.11 & 0.10 & 0.07 & 0.04 \\
\hline Observations & 6,138 & 6,138 & 6,138 & 6,138 & 6,138 & 6,138 & 6,138 & 6,138 & 6,138 & 6,138 & 6,138 & 6,138 & 6,138 \\
\hline Number of firms & 671 & 671 & 671 & 671 & 671 & 671 & 671 & 671 & 671 & 671 & 671 & 671 & 671 \\
\hline
\end{tabular}

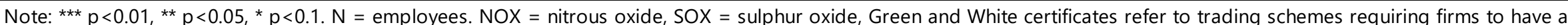
certain share of renewable energy share in total energy, and required energy savings respectively; FITs are feed-in tariffs which are subsidies to renewable energy producers; $\mathrm{PM}=$ particulate matter. Policies lagged one period. 
Table 6: Robustness checks (Specification 2)

\begin{tabular}{|c|c|c|c|c|c|}
\hline & Lag policies & Weighted & Robust SE & Winsorized & Real wages \\
\hline \multirow[t]{2}{*}{ Fossil fuel industries } & 0.00448 & -0.0126 & 0.00980 & 0.0196 & 0.0196 \\
\hline & $(0.0392)$ & $(0.0440)$ & $(0.0454)$ & $(0.0428)$ & $(0.0454)$ \\
\hline \multirow[t]{2}{*}{ High emission manufacturing } & -0.0220 & $-0.0405^{\star \star \star}$ & $-0.0295^{\star}$ & -0.0202 & $-0.0332^{\star \star}$ \\
\hline & $(0.0141)$ & $(0.0150)$ & $(0.0159)$ & $(0.0155)$ & $(0.0159)$ \\
\hline \multirow[t]{2}{*}{ Low emission manufacturing } & 0.0139 & 0.00801 & 0.00726 & 0.00926 & 0.00375 \\
\hline & $(0.0126)$ & $(0.0139)$ & $(0.0144)$ & $(0.0139)$ & $(0.0146)$ \\
\hline \multirow[t]{2}{*}{ Services industries } & 0.0156 & 0.0146 & 0.0208 & $0.0213^{*}$ & $0.0229 *$ \\
\hline & $(0.0121)$ & $(0.0121)$ & $(0.0130)$ & $(0.0128)$ & $(0.0130)$ \\
\hline \multirow[t]{2}{*}{ Construction } & $-0.0744^{\star \star \star}$ & $-0.0527^{\star \star}$ & $-0.0695^{\star *}$ & $-0.0699 * \star$ & $-0.0696^{\star *}$ \\
\hline & $(0.0265)$ & $(0.0252)$ & $(0.0285)$ & $(0.0285)$ & $(0.0287)$ \\
\hline \multirow[t]{2}{*}{ Transport } & -0.0271 & -0.0177 & -0.00417 & -0.00193 & 0.00187 \\
\hline & $(0.0322)$ & $(0.0331)$ & $(0.0342)$ & $(0.0329)$ & $(0.0341)$ \\
\hline Observations & 26,132 & 25,631 & 25,631 & 25,631 & 25,637 \\
\hline Number of firms & 5,332 & 5,305 & 5,305 & 5,305 & 5,305 \\
\hline Joint signficance ( $p$-val) & Yes & Yes & Yes & Yes & Yes \\
\hline
\end{tabular}

Robust standard errors in parentheses. ${ }^{* \star \star} p<0.01,{ }^{* \star} p<0.05,{ }^{*} p<0.1$

Notes: All regressions show interactions with respect to Market EPS. Column 1 considers 1 lag of market EPS. Column 2 considers regressions weighted by (log) employment. Column 3 includes robust standard errors clsustered at the firm level. Column 4 considers winsorized data at the $95 \%$ level. Columnn 5 considers wages deflated by CPI.

\section{Appendix}

\section{Appendix Table A1: EPS and Output gap}

\begin{tabular}{lccc}
\hline \multicolumn{4}{c}{ Lagged policies } \\
EPS: & $\begin{array}{c}\text { Aggregate } \\
\text { Log N }\end{array}$ & $\begin{array}{c}\text { Market } \\
\text { Log N }\end{array}$ & $\begin{array}{c}\text { Non-market } \\
\text { Log N }\end{array}$ \\
$\begin{array}{l}\text { VARIABLES } \\
\quad \text { Threshold: 25th percentile }\end{array}$ & & & \\
Output gap 1/ & $-0.104^{*}$ & $-0.0634^{* *}$ & -0.0890 \\
Output gap X EPS 1/ & $0.0389^{*}$ & $0.0317^{* *}$ & 0.0274 \\
$\quad$ Threshold: 1st percentile & & & \\
Output gap 1/ & -0.650 & -0.859 & -0.156 \\
Output gap X EPS 1/ & 0.293 & 0.493 & 0.0409 \\
Observations & 6,138 & 6,138 & 6,138 \\
Number of panelid & 671 & 671 & 671 \\
\hline
\end{tabular}

Note: ${ }^{* *} p<0.01,{ }^{* *} p<0.05,{ }^{*} p<0.1 /$ Output gap is a dummy variable $=1$ if the real output gap is below the threshold (25th, and 1st percentile of the distribution) shown. "EPS" refers to Aggregate EPS in column 1; Market EPS in column 2; and Nonmarket EPS in column 3. Regressions include all independent variables and controls of Specification 1 (not shown). The coefficients on these variables are similar to those in Table 2B. All policies are lagged 1 period. Panel and year fixed effects are included. Wages, capital, and rental rate are GMM-instrumented with lags. $\mathrm{N}=$ employees.

\section{Appendix Table A2. EPS and Inflation}

Dependent variable
$\mathrm{CPI}$ PPI Expected inflation 1/

\begin{tabular}{lccc} 
EPS & 0.00793 & $0.0177^{* *}$ & $0.0248^{*}$ \\
& $(0.0133)$ & $(0.00782)$ & $(0.0130)$ \\
Lagged dep. var. & $0.535^{* *}$ & $0.550^{* *}$ & 0.276 \\
& $(0.230)$ & $(0.209)$ & $(0.233)$ \\
Output gap & -0.00300 & $0.00548^{* * *}$ & $0.00804^{* * *}$ \\
& $(0.00561)$ & $(0.00195)$ & $(0.00228)$ \\
Observations & 525 & 430 & 525 \\
Number of countries & 31 & 28 & 31 \\
\hline
\end{tabular}

Robust standard errors in parentheses, ${ }^{* * *} p<0.01,{ }^{* *} p<0.05,{ }^{*} p<0.1$ Source: Haver, IMF WEO database and author's estimates. Notes: 1/ 1-year ahead inflation expectations are proxied IMF WEO forecasts for one-year ahead CPI inflation published in the October WEO of each year. PPI includes manufacturing and wholesale price indices depending on data availability. Lagged inflation on the right-hand side is instrumented by further lags following a GMM methodology. Both EPS and output gap are lagged one period. 
Figure 5. Net job impact of tightening EPS (country-wise)

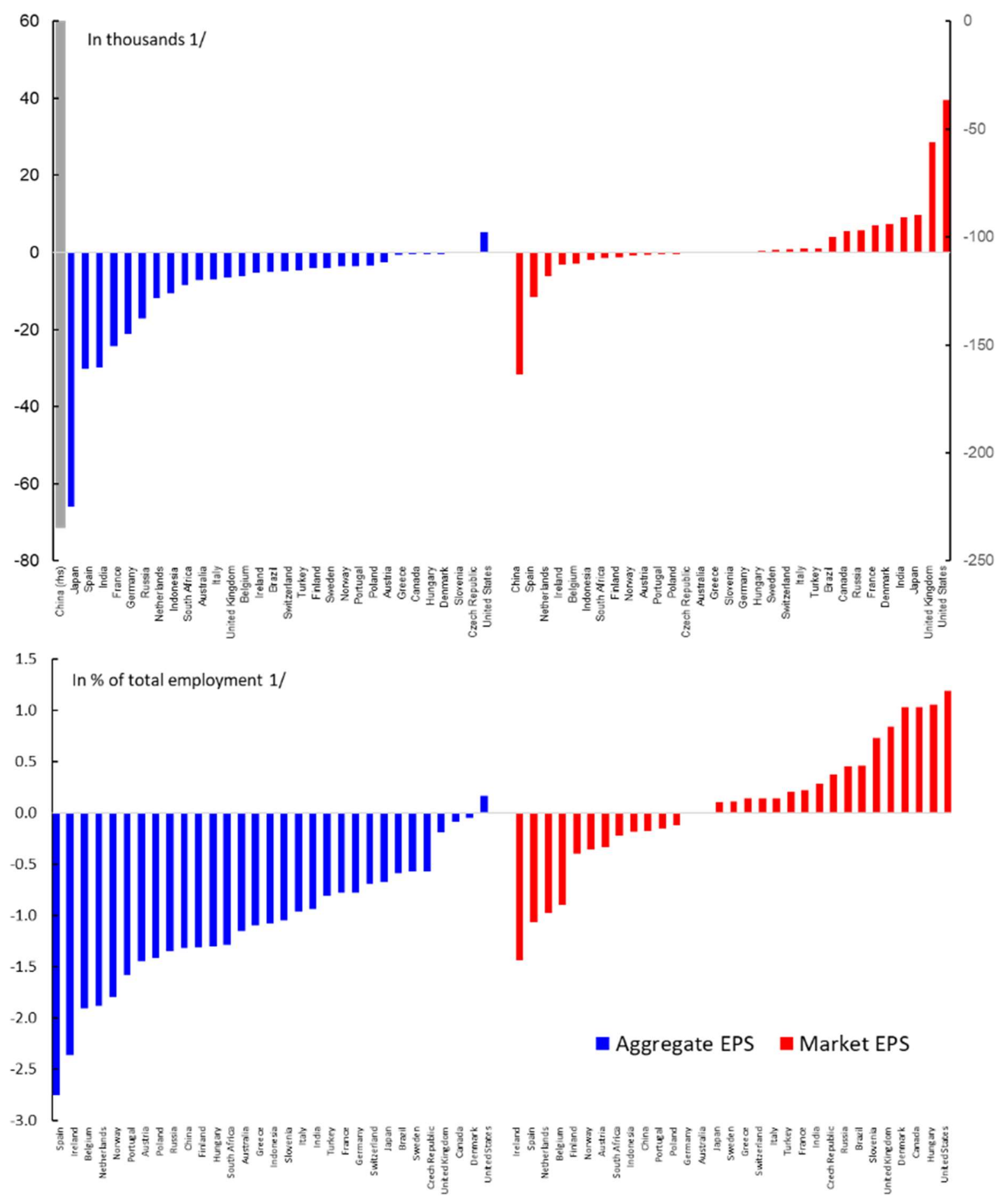

Source: Worldscope database; and author's estimates. Notes: $1 /$ the net job effects are calculated for 2015 , on total employment among 9270 listed firms spread over 31 countries. This set of firms underlies the etimation sample in Table 4, in the year 2015. 